NBER WORKING PAPER SERIES

\title{
ECONOMIC AND SOCIAL IMPACTS OF THE MEDIA
}

\author{
Stefano DellaVigna \\ Eliana La Ferrara \\ Working Paper 21360 \\ http://www.nber.org/papers/w21360
NATIONAL BUREAU OF ECONOMIC RESEARCH
1050 Massachusetts Avenue
Cambridge, MA 02138
July 2015

Prepared for the Handbook of Media Economics, Elsevier. We are grateful to Gordon Dahl, Matthew Gentzkow, Magne Mogstad, Ben Olken, Jesse Shapiro and David Stromberg for comments on the draft. We thank Benedetta Brioschi, Yizhuang Alden Cheng, Brian Wheaton, Martina Zanella, Jeffrey Zeidel, and Michael Zhang for excellent research assistance. Correspondence: sdellavi@econ.berkeley.edu; eliana.laferrara@unibocconi.it The views expressed herein are those of the authors and do not necessarily reflect the views of the National Bureau of Economic Research.

NBER working papers are circulated for discussion and comment purposes. They have not been peerreviewed or been subject to the review by the NBER Board of Directors that accompanies official NBER publications.

(C) 2015 by Stefano DellaVigna and Eliana La Ferrara. All rights reserved. Short sections of text, not to exceed two paragraphs, may be quoted without explicit permission provided that full credit, including (C) notice, is given to the source. 
Economic and Social Impacts of the Media

Stefano DellaVigna and Eliana La Ferrara

NBER Working Paper No. 21360

July 2015

JEL No. A13,D01,D10,H4,I10,I20,J0,K42,L82,L96,O10

\begin{abstract}
$\underline{\text { ABSTRACT }}$
In this survey, we review the literature on the impact of exposure to the media. We cast a wide net and cover media impacts on education, family choices, labor and migration decisions, environmental choices, health, crime, public economics, attitudes, consumption and savings, and development economics. We stress five themes. First, the demand for entertainment plays a key role, with the economic impacts emerging largely as by-products. Second, to understand the media effects one cannot just focus on the direct effect of exposure but one needs to take into account the crowdingout of alternative activities (substitution effect). Third, the sources of identification play a critical role in determining what is known: credible estimates of short- and long run effects are available for some topics and some media but not for others. Fourth, most of the evidence on social and economic impacts is for exposure to the entertainment media such as television, as opposed to the printed press. Fifth, for the policy impacts both the substitution effect of media exposure and the demand for entertainment play an important role.
\end{abstract}

\author{
Stefano DellaVigna \\ University of California, Berkeley \\ Department of Economics \\ 549 Evans Hall \#3880 \\ Berkeley, CA 94720-3880 \\ and NBER \\ sdellavi@econ.berkeley.edu \\ Eliana La Ferrara \\ Universita' Bocconi \\ Dept. of Economics and IGIER \\ via Roentgen 1 \\ 20136 Milano \\ Italy \\ eliana.laferrara@unibocconi.it
}




\section{Introduction}

Does television exposure impair educational achievement? Does violence in the media trigger arousal and violent crime? Can media content affect deep-seated decisions like fertility choices? Is there consistent evidence of imitation of media behavior?

Questions such as these, of relevance to both researchers and policy-makers, have motivated the literature on the impacts of media exposure. In this survey, we review this literature, covering a wide range of economic and social outcomes and summarizing key studies within each area. To maximize readability, we structure the content by field of study, including the topics of education, health, crime, consumption, and family choices. Table 1 provides a summary of the studies we review.

We delineate the content for the survey along three boundaries: outcomes, methodology, and media. In terms of outcomes, while we cast a wide net, the survey will not cover the evidence on the impact of media on politics, covered in Strömberg (2015) and Enikolopov and Petrova (2015), nor the impact of advertising, covered in Wilbur (2015). We also refer to Tetlock (2015) for the analysis of financial choices.

As far as methodology, we examine a variety of evidence from the field, including natural experiments, field experiments, and observational data. We do not instead cover evidence from laboratory experiments or pure survey evidence, methods common in media studies in psychology, political science, and sociology.

Regarding the media covered, we provide evidence on a wide variety of media outlets, from the more traditional ones - radio, movies, and television - to the more modern ones - internet and video games. We do not instead cover the fast-growing literature using text messages and smartphones to deliver content, given the difference in themes. ${ }^{1}$

While we cannot succinctly summarize the results in each of the different fields in this Introduction, we do want to emphasize five recurring themes emerging from the survey: (i) demand for entertainment; (ii) direct versus substitution effects; (iii) identification and time horizon; (iv) the role for entertainment media; and (v) policy impacts.

The first one is the key role of the demand for entertainment. In nearly all the settings we consider, the consumer demand for media content is largely due to demand for entertainment, with the economic impacts emerging as a by-product. Children watch television for its fun value, likely not thinking of possible impacts on education. Adults choose to watch a violent movie or to follow a soap opera for entertainment value, disregarding possible effects on aggression or on family values. This implies that selection into a particular media is likely unrelated to the preference for particular economic outcomes - say, education, violent crime, or fertility. The overarching role of the demand for entertainment is reflected in the fact that people spend

\footnotetext{
${ }^{1}$ While the demand for entertainment plays a key role for the applications we survey, SMS messages are typically used to provide information and reminders.
} 
a large share of time on media entertainment: in the US, the average amount of time spent watching television (which is just one form of media entertainment) is 2.7 hours per day, half of leisure time (Aguiar, Hurst, and Karabarbounis, 2013).

The demand for entertainment differentiates the applications we survey from the analysis of political or financial impacts of the media. The exposure to political information often reflects a direct demand for political content as Stromberg (2015) and Gentzkow, Shapiro, and Stone (2015) stress. The exposure to financial-themed media like CNBC also reflects a direct interest in investment advice.

We incorporate this insight in Section 2 into a simple model of media choice, building on the model in Dahl and DellaVigna (2009). We assume that consumers choose the optimal use of time between several activities, some of which are media activities and some are not. For example, the consumers decide whether to follow a soap opera or to go out with friends. The value of the media activities takes into account the entertainment value as well as cost factors. Similarly, there are utility shifters for the value of alternative uses of time. The activities chosen impact relevant economic outcomes, like education, violent crime, and fertility, but these effects are not considered as part of the utility-maximizing choice, simplifying the analysis. We then derive comparative statics of parameters capturing some of the identifying variation in the media studies.

This takes us to the second key theme, direct versus substitution effects. We stress that there are two main sources of variation of media effects in this entertainment setting. The first one is a shock to the entertainment value of a channel, or to its cost, which affects the audience for a media. For example, violent movies are of higher quality on a particular weekend (a positive demand shock), or soap operas become more widely available in a given year (a positive cost shock). In both cases, as the comparative statics indicates, the resulting media effect estimates incorporate both a direct effect and a substitution effect. The release of a movie like Hannibal at the theater implies that more people will be watching a (violent) movie and thus will be doing less of the second-best alternative activity. The net effect of this shock on crime depends on the comparative effect of violent movies on crime relative to the effect of the alternative activity on crime. Similarly, to understand the impact of introduction of a soap opera, we need to consider the activity and content that it substituted for. Thinking of the substitute activities and evaluating the estimated impact as a net impact relative to substitutes is a key lesson from the studies. Indeed, Stromberg (2015) stresses that a similar direct-versus-substitution effect applies to the interpretation of media effects on politics.

The model also highlights a second source of variation, which is a direct shock to the content of the media. Suppose that an episode of an ongoing soap opera features a gay couple, or an occurrence of suicide. This change in content is likely to leave the utility-maximizing choice of media entertainment mostly unaffected, especially if the content of the episode is unanticipated. Still, the content may affect economic behavior, say through imitation. In this 
case, the estimated media effect captures the direct impact of the media, since the consumption of substitute activities is held constant.

The third key theme for the survey is the role played by identification and time horizon. Take the analysis of imitation of media behavior. A first question of interest is whether there is a short-run imitation effect after a media episode features a particular behavior. A second question is if there are long-term imitative effects of prolonged exposure to the media. To identify the first question, high-frequency variation in the content of a widely-seen media outlet is sufficient. But for the identification of long-run effects, one needs plausibly exogenous variation across places and over time in the introduction of a media outlet which carries unique content. The variation in identification determines the type of media effects one can credibly estimate.

For family choices, we have evidence of imitation in both the short-run and long-run. Kearney and Levine (2014) estimate, among other outcomes, the short-run impact of the US show 16 and Pregnant on Google searches for keywords related to fertility choices. Conversely, La Ferrara, Chong and Duryea (2012) estimate the long-term effects on fertility rates in Brazil of exposure to telenovelas, taking advantage of the staggered introduction of Globo, which largely introduced telenovelas in Brazil.

In most other cases, however, it is not possible to estimate both short-term and long-term effects. In the research on media violence and violent crime, Dahl and DellaVigna (2009) exploit the natural experiment induced by the idiosyncratic release of violent movies to estimate the short-run effects of exposure to media violence. Their design, however, does not lend itself to the analysis of long-term effects. Indeed, to our knowledge, there is no study providing credible estimates of the long-run impact of exposure to media violence. The difficulty is that violent content on the media has been pervasive for a long time, making identification of long-term exposure near impossible, at least in the United States. In cases such as this, it is tempting to look for alternative evidence on long-term effects: indeed, even the American Academy of Pediatrics cites correlational evidence between television usage and violent behavior to support its policy recommendations. Unfortunately, this evidence is plagued by bias - taste for violence is likely to drive both behaviors - and should in our mind be disregarded. In these settings we have credible estimates of short-term effect but are left in the dark regarding long-term effects. In other cases, like the impact of video games consumption on crime, even short-run effects are problematic to estimate because high-frequency variation in video game consumption is very limited.

The fourth theme is the role for entertainment media. A striking feature apparent from Table 1 is the scarcity of evidence about print media: newspapers and periodicals. To put things in perspective, variation in newspaper circulation plays a key role in the identification of political impacts of the media, as local papers provide critical information on local politics (Stromberg 2015). And yet, when it comes to the impact on outcomes such as education, 
health, crime, or family choices, most of the available evidence concerns the entertainment media-television, movies, and internet. ${ }^{2}$

Even within the entertainment media, the evidence available depends also on ability to find identifying variation in exposure, as we stressed above. It is easier to find geographic variation in radio wave penetration or penetration of specific TV channels as driven by geography, cable programming, or content of movies released. It is harder to find credible variation of the penetration of television overall (as opposed to a particular channel), of the internet, or of video games. Thus, we tend to have more evidence on the impact for the first group of media than for the second group of media.

The fifth key theme is policy impacts. A number of the topics we examine reflect policy concerns, like the impact of television and of violent media. Yet, the research papers suggest policy implications which can appear surprising. A first example is that the studies reviewed do not find consistent evidence of a negative effect of television on education (the evidence in this respect is mixed), and find that the availability of violent movies in the short-run leads to reductions, not increases, in crime. The key insight here goes back to the substitution effects: television or violent movies may be substituting other activities that are not better for the relevant outcomes. A second example is that one of the most clearly documented policy objectives achieved by media exposure - the reduction of the fertility rate in developing countries (e.g., Brazil in the 1970s and 1980s) — was attained as a by-product of the success of telenovelas, and was not a goal in the design of the entertainment material. This second example brings us back to the first theme, the overarching role of demand for entertainment.

A more recent set of studies takes stock of the primacy of demand for entertainment for policy purposes, and takes it one step further: why not attempt to incorporate policy goals into the entertainment material? The parallel with advertising is clear: marketing companies have for decades used product placement to sell products, suggesting a natural path for the use of entertainment to 'sell' policies. Still, this strategy faces thorny issues, as one may legitimately worry about its use for propaganda purposes. We return to the issue of "educational entertainment" (or "edutainment"), discussed more in depth in La Ferrara (2015), in the Conclusions.

\section{Methodological issues}

To focus thoughts on the interpretation of media effects, we propose a simple framework highlighting the different channels for the media effects. This model builds on Dahl and

\footnotetext{
${ }^{2}$ This is possibly due to the non-obvious way in which newspaper content on social issues may be coded, compared to political content. For example, measures of ideological bias in newspaper coverage have been proposed comparing the terminology used in the articles to that used by congressmen (e.g., Groseclose and Milyo, 2005) but no similar strategy has been developed for themes related to education, health, etc.
} 
DellaVigna (2009).

Consider a discrete choice model where an audience is choosing between activities $x_{1}, x_{2}, .$. , $x_{n}$. Some of these activities are media choices, such as watching a television show, listening to the news on the radio, or reading a newspaper. Other activities instead represent alternative uses of time, such as attending a group meeting in a village, reading a book, or travelling to a nearby concert.

Assume a standard discrete choice framework with activity $x_{i}$ yielding utility

$$
u\left(x_{i}\right)=X_{i}-\gamma c_{i}+\varepsilon_{i}
$$

where $\varepsilon_{i}$ has a type I extreme distribution. This specification allows for both (i) shocks to demand $X_{i}$ for a media, like the fact that a show becomes very popular, and (ii) shocks to the supply of a media, such as the introduction of a new show, captured by a change in costs $c_{i}$.

The standard logit derivation implies that the share of time spent on activity $i$ will be

$$
s_{i}=\frac{\exp \left(X_{i}-\gamma c_{i}\right)}{\sum_{j} \exp \left(X_{j}-\gamma c_{j}\right)} .
$$

Expression (1) provides intuitive comparative statics for the utility-maximizing consumption of activity $x_{i}$ : the consumption $s_{i}$ will be increasing in its value $X_{i}$, decreasing in its cost $c_{i}$ and decreasing in the quality of the other media $X_{j}$ (for $j \neq i$ ).

The emphasis of this chapter, however, is not on the consumption $s_{i}$ of media activity per $s e$, but on its impact on some outcome of interest $y$. For example, we may be interested in how consumption of telenovelas may affect fertility, how watching television may affect educational attainment, or how watching violent movies may affect crime. We thus consider the outcome variable $y$ (family decisions, education, crime) which is related to the activity choice. For simplicity, we assume a linear relationship

$$
y=\sum_{j} \alpha_{j} s_{j}
$$

That is, each activity $x_{i}$ contributes to the outcome $y$ with a 'direct-effect' coefficient $\alpha_{i}$. For example, say that activity $x_{1}$ is watching a soap opera while activity $x_{2}$ is socializing with friends. We may assume that exposure to telenovelas tends to reduce fertility $\left(\alpha_{1}<0\right)$ while interaction with friends increases it $\left(\alpha_{2}>0\right)$. The direct effect $\alpha_{i}$ could capture for example an imitation effect of the behavior in the media, say because of persuasion (DellaVigna and Gentzkow, 2010).

A key assumption is that the individual does not take into account the impact on $y$ in choosing the utility-maximizing activity $x_{i}$. For example, when choosing a soap opera, the person is not thinking that watching the soap opera will affect his attitudes towards fertility. This is often a plausible assumption, at least in cases in which the outcome is an incidental and plausibly unanticipated by-product. 
The assumption on $y$ implies

$$
y=\frac{\sum_{j} \alpha_{j} \exp \left(X_{j}-\gamma c_{j}\right)}{\sum_{j} \exp \left(X_{j}-\gamma c_{j}\right)} .
$$

This expression allows us to derive a set of comparative statics of determinants of activity choice on the economic outcome $y$, which are the modelling counterpart to the estimates of media effects. The first comparative statics is the impact of a shift in value $X_{i}$, such as the case in which a media outlet $x_{i}$ has become more popular. We derive

$$
\frac{\partial y}{\partial X_{i}}=s_{i} \sum_{j}\left(\alpha_{i}-\alpha_{j}\right) s_{j}=s_{i}\left(\alpha_{i}-\bar{\alpha}\right),
$$

where $\bar{\alpha}=\sum_{j} \alpha_{j} s_{j}$ is the average $\alpha$ across all activities, with weights given by the utilitymaximizing choices $s_{j}$.

Expression (2) highlights three important features. First, the sign of the effect does not depend on the 'direct-effect' coefficient $\alpha_{i}$ per se, but rather on the comparison between the direct-effect $\alpha_{i}$ and the substitution effect, the average $\alpha$ across all other activities, $\bar{\alpha}$. That is, what matters is not whether activity $x_{i}$ per se would trigger behavior $y$, but whether it triggers behavior $y$ more than the alternative activities. The reason is that an increase in the attractiveness $X_{i}$ of activity $x_{i}$ crowds out activities $x_{j}$, and thus affects $y$ through that substitution channel. We are thus going to label this channel the "substitution" channel: the impact of increased exposure to a channel on some outcome $y$ must be evaluated with respect to whatever it substitutes in its time use. So for example if a soap opera becomes more popular, its effect on family outcomes must be considered with respect to the activities that it substitutes, like meeting with friends in a social context.

The second, related point is that the substitution effect depends on the optimal alternative use of time. That is, the net effect depends on $\bar{\alpha}=\sum_{j} \alpha_{j} s_{j}$ which is the average of the effect of the activities $x_{j}$, with weights given by the utility-maximizing choices $s_{j}$. So when comparing the effect of a media shift, one must pay attention to the preferences of the people affected by that shift, since that determines the weights $s_{j}$. For example, in the case of violent movies, the effect of the release of a blockbuster violent movie on crime must be compared relative to the effect of the activities that the relevant group would have chosen otherwise. For people with high taste for violent movies, these alternative activities may be tilted towards other activities with a potential violent component, like getting drunk at a bar. Furthermore, that implies that an increase in exposure to media activity $i$ can have different effects for two different groups, even if all the $\alpha$ parameters are the same, as long as the groups differ in their activity choices $s_{i}$, since that affects the relevant $\bar{\alpha}$ for the group.

The third point stressed by expression (2) is that the effect of an increase in attractiveness of a channel is going to be proportionately larger the larger the share of time $s_{i}$ devoted to activity $x_{i}$. Intuitively, a demand shift to a media outlet will have a larger effect the more 
significant the consumption of the media outlet was. In light of this point, we track as much as possible the intensity of exposure to the media outlet.

We can similarly derive the comparative statics with respect to shifts in the price of a media c. We obtain

$$
\frac{\partial y}{\partial c_{i}}=-\gamma s_{i}\left(\alpha_{i}-\bar{\alpha}\right) \text {. }
$$

The response to price changes is parallel to the response to demand increases, just with the opposite sign.

The third instance of comparative statics which we consider is with respect to a change in $\alpha_{i}$. This comparative statics is relevant when there is a temporary shock to the media programming or content which does not affect consumer demand or cost. Consider for example a popular TV show which features in a particular episode a gay couple. In this case, the unusual programming does not lead to a change in $s_{j}$ given that it is unanticipated, but it may have a direct effect on, say, attitudes towards same-sex relationships (the relevant $y$ variable in this case). Another example would be the news coverage of a prominent suicide case, with the outcome variable being the incidence of suicide cases in the following days. We assume that activity $x_{i}$ on this particular occasion is associated with a different impact $\alpha_{i}$ compared to its normal impact. The comparative statics in this case is

$$
\frac{\partial y}{\partial \alpha_{i}}=s_{i}
$$

An increase in the 'direct-effect' coefficient $\alpha_{i}$ has a bigger effect the larger the share of time allocated to the program. In this case there is no substitution effect, as individuals are not reoptimizing their choices.

We use this framework to highlight plausible interpretations of the media effects for a number of the papers. We stress, though, that for most of the papers it is difficult to disentangle the channels lacking all the relevant information. For a shifter increasing demand for a media, for example, one needs to know the activities that the audience substitutes away from. Such

evidence is rarely available in quantitative format. Nevertheless, we believe that this framework can provide guidance on the interpretation of the media effects.

\section{Outcomes}

We review the impact of media exposure on a series of outcomes. We separate the outcomes broadly by field of study, so as to facilitate the access to researchers interested in a particular topic. We start with the impact of television on education, highlighting both lessons on identification as well as on the direct versus substitution channel.

The next topic, family choices, provides the clearest evidence on imitation of media role models, whereas the following three topics - the study of migration, environmental impacts, 
and health - provide interesting caveats to the imitation effects. The study of crime provides evidence both on the emotional impact of the media and, once again, on the importance of the substitution effect.

Next, we turn to considering the effect on public economics outcomes, first on social capital where the substitution effect plays a key role, and then on attitudes towards taxation and government. Continuing on attitudes, we present evidence on the impact of the media on beliefs regarding other groups in society or the sources of economic success. Finally, we consider the impact on consumption and savings.

Throughout, a number of examples come from developing countries; instead of grouping these examples under a separate 'development' section, we weave in the development economics examples in the relevant topic.

\subsection{Education}

We start by reviewing studies that have explored the relationship between media exposure and education. We consider in depth the education topic to illustrate two of the themes discussed in the introduction: the channels of the effect and in particular the importance of substitution effects; and the key role for identification.

Television (TV) plays a double role with regards to educational outcomes: it provides content but also competes with other activities for time use. Regarding the direct effect, to the extent that TV programs embed useful information and a rich enough language, exposure to this media may increase individuals' knowledge and proficiency with the language. The substitution effect, however, implies that watching TV crowds out activities such as study, social interaction, etc., and thus be detrimental to cognitive and non-cognitive development. A higher amount of time spent in front of TV at early stage of childhood or adolescence thus could induce negative consequences on cognitive development, which is crucial to human capital formation in later years. As Heckman (2000) observes, "success or failure at this stage feeds into success or failure in school which in turn leads to success or failure in post-school learning." The potential negative effect in terms of time use is perceived most acutely for children and adolescents, so many of the studies investigating these issues focus on exposure to television for these age categories.

Zavodny (2006) examines the impact of the amount of time spent in front of TV by young adults on their performance in standardized exams in the United States. The author uses three sources of data, the National Longitudinal Survey of Youth 1979 (NLSY79), the High School and Beyond survey (HSB) and the National Education Longitudinal Study (NELS). She finds a negative correlation between the number of hours spent watching TV and test scores, although the magnitude of the effect is rather small. Furthermore, the above correlations may reflect endogeneity in TV watching, for example if children will less parental support 
in their studies prefer to spend time watching television. The author tries to address this concern using a twofold strategy: on the one hand, she includes individual and family fixed effects; on the other hand, she performs siblings and twins regression, in order to eliminate unobserved household characteristics. Once fixed effects are considered, no significant effect is found: comparisons across siblings, including twins, do not reveal a negative relationship between performance on standardized exams and TV viewing.

While additional controls and sibling fixed effects certainly help, they cannot ultimately fully control for the possibility of selection into television use. If the individuals who watch television more often have characteristics associated with worse educational outcomes, selection biases the outcome. This issue with unobservables plagues the large majority of the early literature on effects of the media, and particular on the impact of television on educational outcomes, since this literature simply compared individuals who self-select to watch a media to others who do not.

To address this important confound, the literature on the economics of the media has achieved identification largely through natural experiments affecting the demand or availability of a particular media. The idea is to find plausibly exogenous reasons which affect media consumption. The first papers using natural experiments in media availability examined the impact on political outcomes: Strömberg (2004) explored the natural variation in radio exposure and Besley and Burgess (2001) used variation in newspaper penetration to test for the effect of the media on responsiveness of politicians to citizen demands. Following up on these papers, Gentzkow (2006) uses the roll-out of the television to test whether it affects turnout to the polls, while DellaVigna and Kaplan (2007) exploit the idiosyncratic availability of Fox News across cable towns to test for a political impact of media bias.

In all of these examples, the identifying assumption is that the availability of a particular media in a location and time is exogenous in a way that selection into listening to a media is not. The papers above use a combination of historical arguments, geographic factors, and documenting selection on observables to make their case. For example, Strömberg uses geographical factors in the availability of radio during the New Deal for identification, while DellaVigna and Kaplan use the fact that the timing of adoption of Fox News by the local cable companies since its inception in 1996 appears to have been largely idiosyncratic.

A relevant case for educational outcomes is the identification strategy used by Gentzkow (2006), which exploits the fact that television licenses were granted in waves with interruptions in the licensing process. The licensing started in 1941, was put on hold between 1942 and 1945 during World War II, restarted after the War and slowed down again from 1948 until 1952. The timing of access to television for a metropolitan area is thus plausibly idiosyncratic. Indeed, the paper documents that the timing of licensing appears to be uncorrelated with a set of demographic variables, conditional on population, income, previous turnout, and region dummies. Gentzkow (2006) then shows that the arrival of television led to a change in the 
pattern of news consumption, and a corresponding decrease in turnout especially in the off-year congressional elections. The finding is likely explained, as in the model above, by a substitution effect: the spread of television led to a decrease in consumption of local papers, which carry the information about congressional candidates. The spread of TV led to less information about the candidates, and lower electoral participation.

We do not dwell in detail on the political effects of the spread of television which are summarized in Strömberg (2015). Still, we summarize the Gentzkow (2006) paper because Gentzkow and Shapiro (2008) use the same identification strategy to study the effect of exposure to television during early childhood on later educational outcomes. The staggered provision of television licenses provides a rare natural experiment guaranteeing variation in television exposure which is not immediately correlated with confounding variables.

It is worthwhile stressing how valuable this particular natural experiment is. A vast literature on the public health effects of television exposure concludes that television generally has adverse effects on child development (Gentile et al., 2004 and American Academy of Pediatrics, 2001). Unfortunately, the large majority of these studies relies on comparing individuals that differ in television consumption, a comparison that very likely is plagued with confounds. Researchers have looked for natural variation in television, but it is hard to come across. Television waves travel across the air over a vast expanse, and nearly all of the United States and most other Western countries have had access to television for decades. There is, simply put, no exogenous variation in overall television exposure in the US for the recent decades that can be used as a natural experiment.

And yet, going back in time, that variation existed, back in the days when television was still in the infancy. That means that, while it is not possible to quantify the impact of today's television on test scores, but it is possible to quantify the impact of television on test scores half a century ago. In fact, the variation is more limited than that. By the time test score data is available for a large enough swath of the population (the educational data from the 1965 Coleman study), there is essentially no variation in television exposure left: all metropolitan areas have good access to television. And yet, there is variation in the length of exposure: for some areas it is just 10 years, for other areas nearly 20 years. Thus, it is possible to compare two groups of 9th graders as of 1965: one group was (potentially) exposed to television since birth, while the second group was not exposed during pre-school, though it also had exposure during elementary school. This design can help us address the question: does exposure to television during the pre-school year have a lasting impact on elementary school achievement?

This is the only question that this strategy allows us to address but, luckily, it is also an important question. Indeed, much of the recent interest in learning in the pre-school years centers on whether early exposure to stimuli has a lasting effect. Gentzkow and Shapiro address this question using data from the Coleman Study - a 1965 survey of standardized test scores for over 300,000 American students in grades 6, 9, and 12-and variation in television exposure 
in the years before.

The first main result is that on average exposure to television during pre-school does not have an adverse impact on educational scores, as one may have worried. Importantly, the results are not due to imprecision of the estimates: the authors can reject an adverse effect of 0.03 standard deviations or more. This contrasts with the common belief that early exposure to television could be a powerful negative force.

The second main result is that there is important heterogeneity in this effect. Among minorities and children of immigrants, in fact television leads to an improvement in educational test score in English, though not in Mathematics. This key result lends itself to a natural interpretation in terms of the substitution effect in (2). Assume that the direct effect of television $\alpha_{1}$ on English test scores (the $y$ variable) of children is the same for natives and for immigrants and is positive, given that television exposes children to spoken English. Still, the two groups differ in that they have a very different mix of other activities $s_{j}$, and thus a different $\bar{\alpha}$. For the natives, television is likely to substitute verbal interactions in English, associated with a relative high $\bar{\alpha}$ - thus the null net effect. But for the children of immigrants, television (in English) substitutes interactions mostly in other languages, which would have a null (or negative) $\bar{\alpha}<\alpha_{1}$. When evaluated against this alternative option, television is a real improvement as far as building English skills for the immigrants. This argument is clearer for English skills than for math skills, consistent with the data.

The key point here is that in asking what television does to education, one need not ask the question, "is television good or bad". Instead, one should ask the question, "Is television better or worse than the alternative option?". This is a key point that we stress at other points in this review and that gets lost surprisingly often.

We are not aware of other papers that provide evidence on educational impacts of the media using equally clear natural variation in media exposure. Still, a number of other papers use observational data to aim to understand the relationship between television and education under a set of identifying assumptions. We discuss this evidence with a caveat about the difficulty of controlling for selection in these cases.

The relationship between television and learning outcomes should not be regarded as a static one: exposure to television can influence cognitive development, which in turn may affect the amount of TV watched in the future. To provide some evidence on this issue, Huang and Lee (2010) develop a two-stage procedure and estimate a "dynamic causal effect". They use the National Longitudinal Survey of Youth 1979 (NLSY79) and estimate the effect of TV watching on child cognitive development, measured through standardized mathematics and reading scores. Once they take into account the dynamic nature of the relationship, Huang and Lee estimate that watching TV for any amount of time during the age of 6-7 and 8-9 has a negative impact on math test scores at ages 8-9, where the negative effects of TV watching at younger ages 6-7 are much larger. In addition, panel data econometric approaches using 
continuous response variables suggest that around two hours spent watching television per day are associated with an improvement in reading scores, while the effects of TV watching on math scores are usually negative. Overall, this paper is consistent with the non-univocal effect of television on education mentioned before: the final impact varies depending on the age at which TV is watched, the subject in which performance is assessed, it is nonlinear and its magnitude is relatively small. Still, one should keep in mind that the evidence used in this paper is based on observational data and cannot take advantage of a natural experiment as in Gentzkow and Shapiro (2008).

At this point, one may wonder what should be the optimal allocation of children's time for the purpose of improving their cognitive and non-cognitive development. An attempt to answer this question is provided by Keane and Fiorini (2014), who investigate how the allocation of children's time among several activities influences cognitive and non-cognitive development. They use the Longitudinal Study of Australian Children (LSAC), which includes 24-hour diaries that allow the authors to measure time inputs such as time spent with parents vs time spent with other relatives, time devoted to educational activities vs time using media, etc. The production function of children's cognitive and non-cognitive skills is allowed to depend on time inputs and parental background characteristics, and the controls include child fixed effects, lagged inputs and lagged test scores. Potential endogeneity of the time inputs, however, remains an issue. The main conclusions of this study are that (i) educational activities like being talked or reading a story are the most productive for cognitive skill development, especially when they are performed together with parents; (ii) non-cognitive skills appear insensitive to alternative time allocations: they are influenced especially by the mother's parenting style (which is captured by two indices of mother warmth and effective mother discipline, using parents' answers to the LSAC questionnaire). Focusing specifically on time devoted to the media, the authors find that media time is not worse than other non-educational activities (like time in before/after school care) for skills development.

The fact that exposure to television could be exploited for educational purposes was recognized early on, giving rise to popular programs such as Sesame Street. Sesame Street can probably be considered one of the largest (and possibly the cheapest) early childhood interventions, although it is not typically considered as such. This show was introduced in 1969 with the aim of improving first grade readiness and reducing the gap between disadvantaged children and better off ones in terms of preschool experience. A recent paper by Kearney and Levine (2015) estimates the effects of this program on educational and labor market outcomes. To identify these effects, they exploit the fact that Sesame Street was initially aired by PBSaffiliated stations, which broadcast on UHF in about half of the cases. Because many TV sets at the time did not receive UHF, and because distance from transmitters also reduced access, about one third of the population did not have access to the show initially. The authors thus exploit variation in coverage across counties and among cohorts (with children younger than 7 
in 1969 considered as 'treated' and older ones as 'control' and adopt a difference-in-differences strategy using data from three Census waves (1980 through 2000).

They find evidence of sizeable and significant impacts during school years: children living in counties with better reception had a higher probability of attending the right grade for their age, especially so if they were boys, non-Hispanic blacks, and living in disadvantaged areas. On the other hand, the evidence is mixed for educational attainment and labor market outcomes: no significant impact is found on high school dropout rates or college attendance, and the effects on employment and wages, albeit marginally significant, are quantitatively very small. Overall these results suggest that the main impact of the program was in improving school readiness, with more nuanced effects in the long run.

Another channel through which media exposure may affect education is not directly through exposure of the children, but rather exposure of their parents or teachers. Using survey data, Keefer and Khemani (2011) study the effects of exposure to community radios in Benin on children's school performance. In Benin, radio is widely used as means of communication and there is a high degree of variation in access across villages. A first channel of the radio effect is through accountability: radio may provide information that households then use to organize collective action and demand better services from the government. In this respect, Benin represents a good setting to explore the accountability channel since it has a relatively long tradition of competitive elections and peaceful turnovers of political power. A second channel for impact comes from the focus of community radios on educational content. Exposure to programming on the importance of education may generate higher parental investments in children's education. In this regard, the radio content in this case is an exception to the general preponderance of entertainment content.

The identification of the effects relies on variation in access to radio generated by accidental features of the topography and signal strength, most notably of out-of-commune radio stations. The results indicate a substantial effect of media exposure on education performance: access to one additional radio station increases the share of literate children by 8 percentage points. If this effect were driven by increased accountability, villages with greater access should see higher government provision of those inputs that are closely related to child literacy (e.g., textbooks per pupil, teacher-pupil ratio, teacher absenteeism, number of classrooms). This does not seem to be the case. Also, access to community radios is not associated with better knowledge by parents of government education policies (e.g., of a massive program to hire new teachers, of test requirements to pass primary school examinations, etc.). Accountability thus seems to play a relatively limited role in the effects on literacy. On the other hand, households with greater exposure to community radios invest more in their children's education (e.g., they buy more books for their children) suggesting that parents' exposure to educational messages leads to positive changes in private behaviors.

To conclude, the empirical evidence on the effect of media exposure on educational outcomes 
is not univocal. Media can be an important vehicle for sensitizing individuals on the importance of education and hence can stimulate parental investments, but when it comes to children's direct exposure to media (especially television), the crowding out of alternative activities can have counteracting effects. Particularly notable in this respect are the differing effects of TV exposure on mathematics versus language test scores found in some of the literature.

\subsection{Family outcomes}

In the previous section on education outcomes, we considered mainly the effect of exposure to television, compared to alternative uses of time. In this next Section, we consider a more detailed channel, and in particular the exposure to role models embedded in the entertainment content on television. To what extent do these role models lead to imitation of their behavior?

We consider the imitation of role models in the media with respect to family outcomes, such as fertility, family planning, age at marriage, and attitudes towards domestic violence. This is an important setting on at least two grounds. First, family choices are of first order importance for both research and policy, especially in developing countries where the reduction of fertility rates is often a policy target. Even setting aside the policy importance, family choices are an ideal setting to test for the importance of imitation: since family choices stem from deep-seated preferences and cultural factors, to the extent that exposure to peer effects from the media leads to changes in behavior, it constitutes a particularly compelling case of media imitation.

We consider the impact of the media on family outcomes mainly in the context of developing countries. In these countries, media exposure vastly increases the availability of information about the outside world and exposure to different ways of life. This is especially true for remote

and rural areas, where television is one of the primary sources through which households acquire information on the life outside their village (Fernandes, 2000; Johnson, 2001; Scrase, 2002). The majority of popular TV programs feature urban settings, whose lifestyles are in stark contrast with those of rural regions. Importantly, the main characters of many soap operas broadcast in developing countries have smaller families, marry later and usually have higher educational attainment than the average viewer. Furthermore, many female characters work outside the home and have significant decision-making power within the household. To the extent that these characters act as implicit role models, exposure to these characters and their ways of life may affect marital outcomes and fertility choices.

La Ferrara, Chong and Duryea (2012) estimate the effect of soap operas on fertility rates in Brazil. Brazil is an interesting case study for two reasons. First, fertility has declined dramatically in a very short time: the total fertility rate went from 6.3 in 1960 to 2.9 in 1991 , without any specific government policy to encourage population control. Second, soap operas (or novelas, as they are called in Brazil), are by far the most popular TV program, and they are broadcast by the media giant Rede Globo, which has basically preserved a monopoly in 
this sector. Interestingly, the timing of expansion of Rede Globo across the country largely coincided with the fertility transition. The authors combine these two aspects and advance the hypothesis that the diffusion of television and the lifestyles portrayed by soap operas may have contributed to the fertility decline. This hypothesis is supported by the content of Rede Globo's telenovelas, which between 1965 and 1999 overwhelmingly showed female characters with no children or one child, in marked contrast with the fertility rates prevalent in society.

To identify the effects of exposure to these programs on fertility, La Ferrara et al. use a difference-in-differences strategy, exploiting the staggered entry of Globo into different municipal areas. Combining Census data with data on antenna location of Globo stations, they find that exposure to the Globo signal decreases the probability of giving birth by 0.5 percentage points (a 5 percent reduction over the mean), which is comparable in magnitude to the effect of increasing a woman's education by 1.6 years. This effect is not driven by pre-trends, and the reduction in fertility begins exactly one year after the entry of Globo in the area. Furthermore, the impact is larger for women of lower socioeconomic status, as one would expect given that these women are less likely to have been exposed to written information on these aspects, and for women who are in the middle and late phase of their childbearing life. These estimates suggest that in the decade 1980-1991 the expansion of Globo accounted for about 7 percent of the reduction in the probability of giving birth.

An interesting aspect of the study by La Ferrara et al. is the attempt to provide direct evidence on the role played by the content of the soap operas leading to imitative behavior. A first piece of evidence is that children born in areas covered by Globo have a significantly higher probability of being named after the main characters of the novela broadcast during the year in which they were born. ${ }^{3}$ Second, the authors exploit variation in the plots over the years, as well as variation in the potential empathy and identification between characters and viewers based on individual factors. They find that fertility decreases by more in years when the plot features upward social mobility, and for women whose age is closer to that of the main female character.

In a separate paper, Chong and La Ferrara (2009) investigate the impact of Brazilian novelas on a different family outcome: divorce. In addition to showing small families, the content of Rede Globo's novelas promoted the circulation of modern ideas, such as women's empowerment and emancipation. Using the same diff-in-diff strategy of the paper above, the authors estimate the effect of exposure to Globo on the probability of marital dissolution. They find that separation and divorce rates increase in municipalities covered by the Globo signal in the years after the arrival of the network.

An influential study on the impact of television on women's emancipation is that by Jensen and Oster (2009). These authors study the effect of the introduction of cable television on

\footnotetext{
${ }^{3}$ This probability is 33 percent for areas covered by Globo and 8.5 percent for those not covered, a significant difference.
} 
women's status in rural India. They use a three-year panel covering 180 villages in five Indian states from 2001 to 2003 and their empirical strategy relies on comparing changes in attitudes towards women between survey rounds across villages, based on whether and when they introduced cable TV: 21 of the 180 sample villages introduced cable during 2001-2003. Given this framework, a crucial empirical issue could be the presence of unobserved factors (such as income or attitude towards "modernity") that determine cable television access and are also correlated with women's socioeconomic status. In order to rule out this concern, the authors adopt a twofold strategy. On the one hand, they show that there are no pre-existing differential trends in women's conditions for villages with and without cable TV and that the timing of changes in the outcomes of interest is closely related with the introduction of the cable. On the other hand, they show that outcomes are not correlated with cable access in the future. They find that exposure to cable is associated with a significant reduction in the number of reported situations in which it is acceptable for a man to beat his wife and a decrease in son preference. In addition, getting cable TV significantly improves women's bargaining power within the household, as measured by autonomy in decision making, and it decreases the likelihood of being pregnant. Finally, they also find benefits for younger children, since the introduction of cable encourages their enrollment in school, an effect that may be driven by the higher participation of women in household decision making.

Decision making and children's educational outcomes have been found to be influenced by the media also in other settings. Cheung (2012) uncovers a media effect in Cambodia, where women's decision-making power within the household and children's primary school attendance increase within the signal range of Women's Station FM 102. This is a popular radio station launched by the Women's Media Center of Cambodia (WMC) in order to change the stereotypes of women in traditional gender roles using an "educational entertainment" approach. To obtain credible causal evidence, two complementing identification strategies are employed. The first one exploits the variation in over-the-air signal strength between radio transmitters and villages within a district due to topographical characteristics (such as the presence of mountains) and it performs a cross-section analysis using individual data from the Cambodia Demographic and Health Survey 2005. The second approach exploits the fact that the radio coverage is gradually expanded over time and across regions to perform a difference-in-differences estimation. Irrespective of the identification strategy, the author observes that radio exposure improves women's bargaining power within the household and children's primary school attendance. The empirical investigation also aims at dealing with possible trends in other factors that might confound the results and potential correlation between the outcome of interest and future radio coverage, concluding that these are not a concern for the identification strategy. Finally, this work provides suggestive evidence on the impact of radio exposure on attitudes towards domestic violence and son preference and this is in line with previous findings presented in this section. 
The persuasion effect of the media when it comes to family outcomes is not confined to the developing world. Kearney and Levine (2014) examine the impact of the widely viewed MTV show 16 and Pregnant (16P), which follows the lives of teenagers during pregnancy and early days of motherhood, on teenage fertility in the United States. The authors employ four distinct sources of data: Google Trends, to capture changes in searches on Google; Twitter, used to analyze all "tweets" made by individuals; Nielsen ratings data to capture geographic variation in TV viewership; and the Vital Statistics Natality Microdata, to measure changes in teen births. The key variation exploited in the paper is the differential viewership across designated market areas, as measured by Nielsen ratings. This creates a potential endogeneity problem, since viewers' interest in $16 \mathrm{P}$ is presumably higher in areas where teenagers are prone to getting pregnant. To address this problem, the authors perform an IV estimation, instrumenting the show's ratings with ratings for all shows that aired on MTV in the four sweeps months preceding the introduction of 16P. The underlying assumption is that ratings obtained before $16 \mathrm{P}$ was created should be orthogonal to subsequent trends in teen pregnancies.

The authors offer three sets of results. First, they document a significant interest in the show: during the weeks in which $16 \mathrm{P}$ is showing, there are clear spikes in Google searches and tweets containing the terms "16 and Pregnant". Second, there is suggestive evidence that the show triggers information seeking on birth control and abortion: on the day a new episode is released, there is a spike in Google searches and Twitter messages containing the term "birth control" and "abortion". Third, the show leads to a 5.7\% reduction in teen births in the 18 months following its introduction, an effect size explaining around one-third of the total decline in teen births in the country over that period. When they split the sample into different age groups, they find that the effect is similar in magnitude and significant up to age 24, while it becomes insignificant for older age groups, consistent with the fact that the viewership of $16 \mathrm{P}$ is relatively young.

To conclude, there is robust evidence that exposure to a particular behavior on television changes behavior in the audience. In most cases, the generally positive media portrayal of a role model leads to imitation, as in the case of Brazilian soap operas leading to lower fertility and higher divorce rates. In other cases, the media portrayal of a difficult situation leads to the opposite behavior, as in the case of 16 and Pregnant. The persuasion effect is consistent across different settings and applies to decisions as consequential as fertility and divorce. Furthermore, the research designs allow us to detect evidence of role model effects not only in the short-run but also in the long-run, after years of exposure. The effect on family outcome is one of the clearest cases of substantial media impacts.

This literature also highlights an important point on identification. In contrast to the effects of television on education where there is little credible evidence, we have quite extensive and detailed evidence on the imitation of family choices seen on television. From a methodological point of view, the key difference is in the variation in media access needed. To examine 
the impact of television overall (say on education) one needs credible variation in exposure to television, which is hard to find. Conversely, to document the impact of imitation of a particular behavior seen on television, one needs variation in a particular show with unique content, which is easier to find.

\subsection{Labor markets and migration}

In the same way that television delivers information on family choices, it also exposes viewers to information regarding labor market opportunities, both domestically and abroad. Especially in developing countries or lower-income areas within a country, television exposes viewers to higher standards of living. The imitation hypothesis holds that exposure to these lifestyles induces attempts to emulate them, including migrating to higher-income areas and countries. The evidence on this topic turns out to be more nuanced than that.

A first piece of evidence is provided by Braga (2007), who investigates the impact of Italian television on individual migration decisions in Albania. The Albanian case is emblematic, since both economic and political contact with the rest of the world were absent during the communist regime. From 1941 to the late 1980s, the media and broadcasting system was strictly controlled by the Communist party and there was only one national television channel, broadcasting propaganda and politicized documentaries. However, although foreign TV was forbidden, Albanians could easily watch Italian TV starting from the early 1960s, due to geographical proximity between the two countries.

Italy has experienced a large inflow of immigrants from Albania in recent decades. To test if this can at least in part be attributed to Italian television, Braga (2007) uses data from the Albanian Living Standard Measurement Survey and estimates individual migration status as a function of a number of controls plus foreign media exposure. Exposure to foreign television is measured by the shortest distance between the location of Italian transmitters and the place of residence of the respondent (in Albania). The results show that the probability of migrating significantly increases the shorter is the distance from Italian transmitters $(0.7$ percentage points for every additional kilometer). This is a large effect, considering that the baseline rate of international migration is 8 percent. Furthermore, exposure to Italian media increases migration not only to Italy but also to other countries, suggesting that images on Italian television favored Albanians' openness towards other countries.

Interestingly, Farré and Fasani (2013) reach an opposite conclusion for the case of Indone-

sia. Using the Indonesian Family Life Survey (IFLS) and The Village Potential Statistics (PODES), they investigate the effect of media exposure on internal migration in Indonesia. In particular, they exploit the differential introduction of private TV throughout the country and the variation in signal reception across districts due to topography. They consider both "early" exposure to television during adolescence and "current" exposure. The first variable is 
motivated by the fact that migration movements usually occur at a young age, thus individuals may be substantially influenced by expectations formed early in life. The second variable captures the fact that individuals also update their expectations when new information becomes available. The authors uncover a negative effect of both early and current TV exposure on the propensity to migrate: a one standard deviation increase in exposure to television decreases the overall migration rate by $8-15 \%$ of a standard deviation, depending on the model specification.

How does one reconcile the two findings? As Farré and Fasani suggest, the imitation hypothesis is somewhat simplistic: one should not expect that all role models presented in the media would lead individuals to attempt to imitate them. In many circumstances, it is reasonable for media audiences to update on a particular behavior in the direction of the role model. In other cases, however, the updating could go the opposite way: exposure to a behavior on television could lead audiences to change their beliefs in a way leading to behavior opposite the role model. In the Indonesian case, it is possible that Indonesian citizens prior to the expansion of private TV broadcasting were too optimistic in assessing the potential gains from moving, and that television helps to correct this optimism.

This is an important caveat to keep in mind when studying the impact of media role models: the effect of what people see on television or hear on the radio depends on content not only in "absolute" terms, but relative to the baseline values and beliefs held by the individuals. It is thus very helpful if information on baseline beliefs and values is available so as to accurately interpret the empirical findings.

Another dimension in which exposure to the media can affect labor market outcomes is by influencing occupational choice. Bjorvatn et al. (2015) analyze a field experiment with around 2,000 secondary school students from Dar es Salaam, Tanzania. The experiment consisted in encouraging students and their families to watch an educational TV show about entrepreneurship, business skills and financial literacy. A total of 21 school were randomly assigned to watch this show, while 22 schools were assigned to a control non-educational movie. The educational show consisted of 11 weekly episodes on the lives of six young entrepreneurs (males and females). The authors estimate both short-term effects and long-term (two years after the end of the show) impact on a number of variables. In the short term, the show is effective in increasing ambition and some entrepreneurial traits (measured through lab experiments), and this maps into a differential propensity to starting a business which persists in the long run: two years later, the probability of having started a business is about 9 percentage points higher for the treatment group, representing a 30 percent increase relative to the mean for the control. Interestingly, there is no impact on business knowledge in the short run. An important result in the paper is that the show has a negative impact on school performance in the long run: treated students are less likely to pass the final exam and to continue studying beyond secondary school. While this result may be specific to the Tanzanian context, where the quality of formal education may have been considered by the participants relatively low, 
it does caution us about possible unintended effects of the instrumental use of television for 'educational' purposes.

\subsection{Environmental economics}

In this section, we examine the extent to which documentaries, which often have the purpose of changing behavior, achieve their goals by triggering imitation of a desirable behavior. Within the field of environmental choices, a good example is the documentary An Inconvenient Truth by $\mathrm{Al}$ Gore, which presents in dramatic fashion the evidence on global warning and suggests the need to act. Did it then affect environmental choices? Notice that this example differs from the "edutainment" examples, since An Inconvenient Truth was not conceived as entertainment, but rather as a content-packed exhortation to action.

Jacobsen (2011) examines the impact of exposure to this movie on a form of environmentalism, the purchase of carbon offsets. For identification, the author exploits closeness to the nearest movie theater that showed An Inconvenient Truth. The difference-in-difference specification shows an increase in carbon offset purchases of about 50 percent relative to the baseline for individuals living within 10 miles of a movie theater showing the movie. Still, it is quantitatively a relatively small increase given that the baseline purchases are quite limited, and it is a transitory effect, with no evidence of persistence a few months later.

There is a natural comparison between the effect of a documentary intended to persuade versus the evidence from entertainment options like telenovelas which are not per se intended to change behavior. Documentaries can indeed have an impact on behavior as the Jacobsen (2011) paper stresses; however, this impact is likely to be limited given that the audience interested in documentaries is relatively small and mostly consisting of individuals already embracing a cause. In contrast, entertainment shows reach millions of individuals across all walks of life: the large and persistent impact documented on family choices by La Ferrara, Chong and Duryea (2012) is particularly striking given the cultural values associated with choices such as the number of children.

\subsection{Health}

As for the case of family choices, migration, and environmental choices, researchers have considered the effect of media exposure on health. Most papers examine the impact of information about desirable (or undesirable) health behavior contained in media programming. Surprisingly given the interest in health economics, the evidence is limited and mostly comes from outside economics, such as health and communication studies. The estimates often lack a convincing design, document only short-run effects of exposure, or employ an outcome variable

that is an indirect measure, such as the number of calls to a hotline, as opposed to the ultimate variable of interest. 
Suicide. The literature on suicide provides an example of the promise and limitations of the existing health evidence. A motivation for the studies on suicides is the worry that media coverage of the suicide of a celebrity may lead to a wave of suicides among vulnerable individuals in a copycat effect.

In a prominent series of early papers, David Phillips and coauthors find that the occurrence of suicides appears to increase after major suicide episodes are in the news. In a representative paper, Bollen and Phillips (1982) use the Vanderbilt data set of television news stories on ABC, CBS, and NBC to code all stories under the heading 'suicide' broadcast between 1972 and 1976. They then link the data to the U.S. daily suicide statistics. In a time series regression with seasonality controls, the authors find evidence of a significant increase in suicides occurring on the first two days and on days 6-7 after the story. The coefficients, which are significant at the 5 percent level in a one-tailed test, imply an overall increase of 28 suicides for each suicide story, a large imitation effect.

In a follow-up study, however, Baron and Reiss (1985) show that the evidence in Bollen and Phillips (1982) and in other related papers is not reliable. First, the imitation effect is not statistically significant if one considers all lags jointly, rather than focusing only on the significant ones. Second, the effects appear due to improper controls for seasonality. Indeed, when running a placebo regression which lags the suicide story by exactly one year and thus keeps constant the seasonality structure, the authors find similar imitation effects, pointing to problems in the econometric specification.

Follow-up studies in the thirty years since number in the dozens in sociology and medical journals. Still, in our reading the evidence on imitation of media portrayals of suicide is not convincing. A comprehensive study with attention to the channels and to confounding factors is missing.

Smoking. Smoking remains the most important avoidable public health risk in the United States and in a number of countries. What do we know about the impacts of exposure to media content on smoking? Since advertising by cigarette companies has been severely limited in the United States in the recent past, most media studies focus on the impact of anti-smoking media campaigns on smoking.

Bauman et al. (1991) examine a field experiment on smoking cessation messages broadcast via radio in the U.S. South. Two MSAs served as treatment groups and four as control MSAs, and in these MSAs about 2,000 adolescents were surveyed one and a half years after the exposure to the radio messages. The evidence suggests that the messages affected the self-reported valuation of smoking, but not smoking rates.

While the previous paper examined randomized exposure on a small sample, Farrelly, Nonnemaker, Davis, and Hussin (2009) evaluate the exposure to the national 'truth' smokeprevention Campaign that was launched in 2000 in the U.S. The roll-out of the 'truth' campaign, however, was not randomized, so the analysis is based on comparisons across media 
markets controlling for observables. Using NLSY data on smoking initiation, the authors estimate that the media campaign significantly reduced smoking initiation by as much as 20 percent.

These two representative papers in a vast literature provide suggestive evidence on the impact of anti-smoking campaigns. While the evidence is in our reading of higher quality than the evidence on suicide imitation, we are not aware of a study that combines the strengths of the two papers above - a clear design for identification and large scale evidence - without the respective weaknesses.

HIV/AIDS. As a third outcome, we consider the impact of media exposure on HIV prevention. In this case, the two papers we review examine the impact of educational messages embedded within entertainment content.

A first piece of evidence is provided in a study on HIV prevention in Tanzania by Vaughan, Rogers, Singhal and Swalehe (2000). They evaluate the effects of an educational-entertainment radio soap opera, Twende na Wakati (Let's Go with the Times) on knowledge, attitudes and behaviors towards HIV. HIV rates in Tanzania are among the highest in the world, and radio is one of the most important sources of information regarding AIDS in the country. Radio Tanzania, together with the government and UNFPA (United Nations Population Fund), produced this soap opera to convey messages regarding HIV prevention, family planning, gender equity and other health-related themes. The program was broadcast twice a week for 30 minutes from 1993 to 1999. To evaluate its effects, Vaughan et al. exploit the fact that the soap opera was not broadcast by the Dodoma regional transmitter from 1993 to 1995, allowing the use of this region as a "control group". The authors compare outcomes before and after exposure to the radio program across treatment and control locations, and find that it was effective in promoting HIV-responsible behaviors, e.g. reducing the number of sexual partners by both men and women and increasing condom adoption.

Additional evidence in a different setting is provided by Kennedy, O'leary, Beck, Pollard and Simpson (2004). In their work, media impact is measured by the total number of calls received by the CDC National STD and AIDS Hotline after the introduction of a subplot regarding AIDS in the soap opera The Bold and The Beautiful in the US. Calling this hotline is employed as a proxy for health information seeking behavior. After two of the episodes -when a character was diagnosed with HIV and when he told his partner- the toll free number of the hotline was displayed on screen. The study reports a large increase in the number of attempted calls on the days of the two episodes, in the time slot during and immediately after the soap opera broadcast. This suggests that the soap opera is effective in sensitizing viewers towards HIV/AIDS.

While the above studies provide suggestive evidence that TV and radio soap operas can be effective in sensitizing people to health issues, more work is needed to credibly establish a causal link and to understand if the positive effects found shortly after the exposure persist in 
the long run. The recent work by Banerjee, La Ferrara and Orozco (2015), which we briefly discuss in the conclusion, is an attempt to make progress in both directions.

\subsection{Crime}

For our sixth topic, we consider the impact of the media on crime, and especially violent crime. A leading research hypothesis akin to the imitation hypothesis studied in the context of family choices and immigration is that exposure to violence leads to arousal, triggering further violence. The converse hypothesis also has followers: exposure to media violence has a cathartic effect, freeing potential aggressiveness and lowering real-life violence.

Whether media violence triggers violent crime has clear policy implications. Indeed, in 2000, the American Medical Association, together with five other public-health organizations, issued a joint statement on the risks of exposure to media violence (Cook et al., 2000). The evidence cited in these reports, surveyed by Anderson and Buschman (2001) and Anderson et al. (2003), however, does not establish a causal link between media violence and violent crime. The evidence on the topic is of two types, experimental and correlational.

The experimental literature consist of exposing subjects in the laboratory (typically children or college students) to short, violent video clips. An example is Josephson (1987) who randomizes exposure to short violent clips versus clips with action scenes, but no violence. After the media exposure, the subjects play a game of hockey, and the group exposed to violent clips is more likely to engage in aggressive play. These experiments typically find a sharp increase in aggressive behavior immediately after the media exposure, compared to a control group exposed to non-violent clips, supporting the arousal hypothesis. This literature provides causal evidence on the short-run impact of media violence on aggressiveness. However, this evidence does not address whether this translates into higher levels of violent crime in the field.

A second literature (e.g., Johnson et al. 2002) documents that survey respondents who watch more violent media are substantially more likely to be involved in self-reported violence and criminal behavior. This correlational evidence, while indeed linking media violence and crime, has the standard problems of endogeneity and reverse causation. The individuals who watch more violent television are not comparable to the ones who do not, confounding the correlation.

Dahl and DellaVigna (2009) propose a different strategy to capture the impact of violent media on actual violent crime without the confounds of endogeneity. Namely, they exploit the natural experiment induced by time-series variation in the violence of movies shown in theaters. Using a violence rating system from kids-in-mind.com and daily movie revenue data, they generate a daily measure of national-level box office audience for strongly violent (e.g., "Hannibal"), mildly violent (e.g., "Spider-Man"), and non-violent movies (e.g., "Runaway Bride"). Since blockbuster movies differ significantly in violence rating, and movie sales are 
concentrated in the initial weekends after release, there is substantial variation in exposure to movie violence over time. The audience for strongly violent and mildly violent movies, respectively, is as high as 12 million and 25 million people on some weekends, and is close to zero on others. This variation creates the conditions for identification using time-series variation. The authors match this data to crime data from the National Incident Based Reporting System (NIBRS) to estimate the short-run impact of exposure to violent media on violent crime. Notice that the short-run (as opposed to long-run) impact is what the laboratory experiments also capture, and is the relevant variation to identify the arousal hypothesis.

The results appear to contradict the laboratory evidence supporting the arousal hypothesis: on days with a high audience for violent movies, violent crime is lower, even after controlling flexibly for seasonality, weather and other potential confounds. Breaking down the effects into time blocks, which is possible given the granularity of the crime data, helps assess the channel of the findings. There is no effect in the morning or in the afternoon before movie exposure, as one would expect. In the evening hours (6PM-12AM), for each million people watching a strongly or mildly violent movie, respectively, violent crimes decrease by 1.3 and 1.1 percent, a statistically and economically significant impact. In the nighttime hours following the movie showing (12AM-6AM), the delayed effect of exposure to movie violence is even more negative.

Is the negative effect then evidence of a cathartic effect? Not so fast. Returning to the model in Section 2, the relevant variation for identification is in the quality $X$ of violent versus non-violent movies, leading to sharply different audiences on different weekends. As the model makes clear, this variation identifies the net effect on crime of exposure to violent movies versus the next best alternative use of time, that is, $\alpha_{v}-\bar{\alpha}$. Even if violent movies trigger crime, that is $\alpha_{v}>0$, the estimated impact on violent movies will be negative if alternative activities trigger crime at an even higher rate, that is $\alpha_{v}<\bar{\alpha}$. With this in mind, the negative effect in the evening hour reflects the voluntary incapacitation of individuals into the movie theaters, a low-crime setting compared to almost any alternative: thus, surely $\alpha_{v}-\bar{\alpha}$ is negative.

In the night hours, though, the theaters are closed: how should one interpret the results? The findings indicate that spending an evening at the movie theater leads to less violent behavior in the night thereafter compared to the alternative activity that the (potentially violent) audience of the movies would have chosen. A natural channel is alcohol: individuals who spend two or more hours at the movie theater in the evening are more likely to be sober by midnight compared to spending the evening at a bar or drinking with friends. Dahl and DellaVigna (2009) provide some direct evidence on this channel: If alcohol is a key channel, the effect of movie exposure should be larger for people who are barely of drinking age (2124 year olds) compared to people who are barely below drinking age (17-20 year olds), since drunkenness is significantly less likely in this second group. Notice that the comparative statics here exploits variation in $\bar{\alpha}$, the impact of the alternative option, across the two groups, holding constant $\alpha_{v}$. This comparison is akin to the comparison in the effects of television between 
natives and immigrants in Gentzkow and Shapiro (2008). Consistent with an important role for intoxication, the negative impact of exposure to violent movies on crime is large and negative for individuals aged 21-24, but close to zero for individuals aged 17-20.

What does one learn from a natural experiment of this type? The identification of the impact of violent media relative to the alternative option, that is, $\alpha_{v}-\bar{\alpha}$, provides some relevant policy counterfactuals. For example, based on these estimates, a policy that would ban violent movies on certain weekends would increase assaults by roughly 1,000 occurrences per weekend given the ensuing shift to more dangerous activities. ${ }^{4}$ The estimates, however, do not tell us whether exposure to violent media per se leads to arousal $\left(\alpha_{v}>0\right)$, catharsis $\left(\alpha_{v}<0\right)$, or neither. One can, however, estimate the direct effect of exposure to violent movies $\alpha_{v}$ under some assumptions about the effect of alternative activities. Under one such set of assumptions, Dahl and DellaVigna (2009) decompose the observed effect into a direct effect $\alpha_{v}$ and a substitution effect $\bar{\alpha}$ and find that the evidence is most consistent with the arousal hypothesis: the direct effect of exposure to violent movies is to increase violent behavior $\left(\alpha_{v}>\right.$ 0 ). Thus, the field evidence is consistent with the laboratory findings, once one does the proper comparison. Yet, this decomposition is more tentative given the additional assumptions needed; additional evidence that is able to parse the different parameters would be very valuable.

A second point is that this evidence does not teach us anything about the long-term effects of exposure to violent media. Given the high-frequency nature of the instruments, the authors can examine the effects within a month of exposure (finding no evidence of a delayed impact on crime), but cannot pin down the long-term effects, which is a key question for policy. To identify such effects, one needs variation in prolonged exposure to a media, as in La Ferrara, Chong and Duryea (2012) or Gentzkow (2006). Unfortunately, we are not aware of any such evidence that plausibly varies the long-term exposure to violent media. We stress that correlational evidence between media use and violence as in Johnson et al. (2002) is no substitute for this evidence, and should not be used for policy recommendations.

Returning to the role of arousal in violent crime, an alternative identification strategy is variation in media content, holding constant the use of time. That is, suppose that individuals are exposed to a particular media program which they choose for entertainment value, but the content of the program varies in its arousing content in unexpected ways. As the model in Section 2 details, this direct comparative statics on $\alpha$ would uncover the direct effect of media arousal, given that there is no substitution to other activities.

While we are not aware of a paper using this identification for media violence, Card and Dahl (2011) use it to identify the impact of emotions, in particular disappointment and elatedness, on violent crime, and more specifically domestic violence. The motivation for the paper is

\footnotetext{
${ }^{4}$ More generally, this research is consistent with the hypothesis that other activities with a controlled environment that attract young men, like Midnight Basketball proposed by Bill Clinton in the 1990s, would also reduce crime in the short run.
} 
understanding the role of emotional triggers on domestic violence. In the paper, emotional triggers are the results of football games broadcast via television. The design allows the authors to distinguish between the impact on fans of the winning versus losing team based on the location of the domestic crimes in the NIBRS crime data.

An appealing feature of the research design is that it allows for a measure of expectations, and deviations from such expectations, with the resulting emotional trigger. Namely, the authors use the betting line to measure expectations about outcomes of football matches so they can distinguish between expected and unexpected losses, and between expected and unexpected wins. The authors then measure domestic crimes in the hours surrounding the game.

The results point to the importance of disappointment for violent crime: unexpected losses increase domestic violence by 7 percent, compared to the expected result (a win). As one would expect, the effect is larger for more important games and it is entirely driven by violence of men on women and not by violence of women on men. Furthermore, the effect disappears within a few hours of game end, consistent with the impact of transient emotions. In comparison, there is no converse effect of a positive surprise: there is no evidence that a surprising win (compared to the expected loss) lowers violent crime.

These results indicate that the triggers of violence originating from the media need not be violent themselves: in this case, the emotional trigger is disappointment from an unexpected loss.

So far, we have discussed the potential impact on crime of exposure to two traditional media outlets, movies and television. Yet, access to Internet and broadband access introduces its own potential for an impact on crime. In particular, access to the internet introduces access to content that is harder to find in traditional media, such as pornography. As such, some researchers have worried that the spread of the internet may lead to a spike in sex crimes to the extent that sexual arousal leads to sexual aggression. Alternatively, it is also possible that pornography may be a substitute for sexual assaults, rather than a complement.

There are two main difficulties in documenting the effect of access to pornography via internet on outcomes such as crime. First, the internet provides access to a bundle of content, of which pornography is only a part (if one with heavy traffic); thus, one should speak of the effect of the internet overall, rather than of its individual components. Second, internet access in most countries such as the United States expanded in a relatively linear fashion over time, making identification difficult.

Bhuller, Havnes, Leuven, and Mogstad (2013) provide evidence from Norway where a public program with limited funding rolled out broadband access points in 2000-2008, providing plausibly exogenous variation in internet use across different municipalities over time. The authors adopt an IV strategy, instrumenting the fraction of households with broadband internet subscriptions in a given municipality/year with the fraction of households that were covered by 
the relevant infrastructure in the previous year. They find that exposure to internet content significantly increased the number of sex crimes, with the impact occurring in the year of the increased coverage, and lasting over the next two years. The effect is sizeable: during the sample period about $3.2 \%$ of the total number of rapes and $2.5 \%$ of the total number of sex crimes and child sex abuses can be attributed to broadband internet exposure.

To pin down the interpretation of the results, the authors consider additional results. A first possibility is that availability of the internet changed reporting of sex crimes, with no changes in the underlying occurrence. There is, however, no evidence that the types of reported crimes have changed over time along the lines one would expect if this were the case. A second possibility is that the internet may have increased the match rate between potential offenders and victims, while a third possibility is that the effect occurs through an arousal effect. While it is difficult to separate the last two channels, an interesting source of variation occurs in the alternative choices available, namely non-internet pornography. Since pornography is banned in Norway but allowed in Sweden, Norwegians living near the border with Sweden are likely to experience a smaller impact of the internet, especially if the channel is arousal. Indeed, the impact is larger further from the border.

Bhuller et al. (2013) also stress the importance of identifying the media users who are on the margin of media adoption, or technically the compliers in the IV local average treatment effect. This is the population that is induced to internet consumption due to the recent expansion of infrastructure. Survey data on internet consumption shows that young males are overrepresented among the compliers. Similarly, Dahl and DellaVigna (2009) show that violent movies are more likely to draw an audience of young males compared to other movies. The self-selection into media adoption plays an important role in understanding the media effects. The model stresses this role in that the substitution effect $\bar{\alpha}$ must be evaluated with respect to the activity choice $s_{i}$ of the relevant individuals, the compliers. This relevant population, with young males overrepresented, could else differ in the crime effects $\alpha_{i}$ compared to the rest of the population. This becomes particularly relevant when extrapolating the media effects to another population. For example, as the internet roll-out continues, the marginal users may have a lower propensity to violence compared to young males, or different substitution patterns.

Aside from the internet, a different modern media with a possible relationship to crime is video games. On the one hand, some experts worry that violent video games may trigger aggression as in the arousal hypothesis. On the other hand, having potentially violent individuals spend much time playing video games may induce substitution away from more dangerous activities, leading to a reduction in crime.

Unfortunately, even setting aside the identification of long-run effects, the identification of short-run effects of exposure to video games is more difficult than the analysis for violent movies, on two grounds. First, while one can obtain weekly measures of the sales of new video 
games similarly to weekly measures of movie audience, for video games the sale represents just the beginning of a period of play, while for movies purchase equals consumption. This weakens significantly the power of the instrument induced by timing of release. Second, the release of major new video games displays a massive spike around Christmas that is more accentuated than the spikes for releases of movies. This further limits the remaining variation after controlling for seasonality. In this light, the evidence in Cunningham, Engelstätter, and Ward (2011) of a negative relation between video game sales and violent crime should be seen as a tentative assessment. Hopefully, future research will suggest sources of variation to precisely pin down the impact of video games, a topic of real importance given the significant number of hours spent by the youth on video games.

\subsection{Public economics}

In this section, we review the effect of media coverage on a set of public outcomes, including participation in social organizations and attitudes towards the government. In this respect as well, it is helpful to return to the direct effect and substitution effect of media coverage. The direct effect is such that, if media outlets convey information on politicians' performance, they can affect individuals' trust toward government, tax compliance and knowledge of public policies. This is a point studied since the seminal papers by Strömberg (2004) and Besley and Burgess (2001) and surveyed in Stromberg (2015). At the same time, through a substitution effect, exposure to mass media can have detrimental effects on social capital, since the large amount of time spent in front of $\mathrm{TV}$ or listening to the radio can crowd out significant social activities.

The latter point was originally made by Putnam (2000) in his influential 'Bowling Alone' book. The contention in the book is that the availability of television and other modern entertainment possibilities have contributed to isolate individuals who previously used to spend leisure time in social activities like going bowling together. In turn, this leads to a loss in social capital.

Olken (2009) provides evidence on this in a study of the impact of television and radio on social capital in Indonesia. He exploits two different sources of exogenous variation in the number of television and radio channels that households receive. First, he takes advantage of the differential introduction of private television in the country between the 1990s, when there was just one government TV station, and the mid-2000s, when eleven TV channels were present in Indonesia. Second, he considers the variation in the propagation of the signal due to topographical and geographical conformation of the territory (for instance, the presence of

mountains in Central and East Java generates a variation in TV reception that is unrelated to village characteristics). Specifically, he adapts the Irregular Terrain Model by Hufford (2002), which predicts that locations in direct line of sight to a transmitter will receive the strongest 
signal, while if mountains block sight lines, the signal will diffract around the mountains and signal strength will depend on the frequency of the signal. This approach has since been used in a variety of studies of television and radio effects.

In the first set of results, Olken uses the number of channels received by each subdistrict as a proxy for TV and radio exposure. In a first stage, the reception of an additional channel is associated with 14 additional minutes per day spent watching TV and listening to the radio. In the second stage, each additional channel received is associated with about 7 percent fewer social groups existing in the village and 11 percent lower attendance at meetings, suggesting a significant negative impact of television on social capital. The author finds similar results when introducing the model of electromagnetic signal propagation to isolate the effect of topography: greater TV reception is associated with lower levels of participation in village development meetings and with lower levels of self-reported trust.

Olken also explores the relationship between media exposure and governance. As a measure of governance, Olken uses attendance at village level meetings that planned and monitored roads construction, the quality of discussion at those meetings and the percentage of funds used in the project that could not be accounted for by an independent engineering team. Despite finding a negative impact of television access on attendance at village meetings on the roads project, he finds no impact on what happens during these meetings and on "missing expenditures" in the road project. Altogether, media exposure can lead to a significant decrease in participation in social activities and in self-reported trust, especially if it appears to substitute group activities. However, the link to government outcomes is unclear, at least in this study.

While Olken's paper is focused on pernicious effects of television, television programming also offers positive opportunities. In particular, entertainment TV programs can be used to convey information regarding government's action and programs and, under some circumstances, they can encourage support and trust toward the government. In this direction, Trujillo and Paluck (2011) show that a specifically designed soap opera can influence political attitudes and engagement. The authors test the impact of the telenovela Más Sabe El Diablo (The devil knows best), a Spanish language soap opera broadcast by Telemundo which portrays Latino characters' involvement with the 2010 Census. The Census has historically had trouble estimating the Latino population living in the US for two main reasons: the difficulty faced by Spanish-speaking individuals in understanding the information about the census and completing the forms, and the diffused lack of trust in government authorities, in particular regarding the use of the information collected. The latter reached a peak in 2010, when Latino religious leaders organized a boycott of the Census with the objective of pressing the government into enacting immigration reforms.

Given this scenario, Trujillo and Paluck investigated whether a telenovela could affect census attitudes and engagement among US Latinos. During the census collection period, they organized a hybrid lab-field experiment and randomly assigned Latino community members in 
Arizona, New Jersey and Texas to watch pro-Census scenes or control scenes that featured the same character but not the Census. The census clip overall had a positive effect: compared to control viewers, census viewers expressed more positive attitudes toward the US government and displayed more behavioral support for the Census, for instance by wearing pro-Census stickers and taking informational flyers. This effect is interestingly heterogeneous. In Arizona, which had recently passed anti-immigrant legislation (Senate Bill 1070), the attitudes towards the government were actually worse among the group that watched the Census clip. This suggests that the local context plays a critical role in mediating the effect of media programs on outcomes.

Additional evidence on the effect of media on trust and attitudes' toward the government is provided by Kasper, Kogler and Kirchler (2015). They address the question of how taxpayers' perceptions of government and tax authorities are influenced by media coverage. In order to do so, they randomly assign a sample of 487 employees living in Vienna to a $2 \times 2$ media manipulation exercise, randomizing trust in authorities (low/high) and perceived enforcement power of authorities (low/high). The treatments consists in media reports on trust and power. In the high trust scenario, the political situation in Austria is described as very stable, while in the low trust scenario, Austria is described as a country with relatively low political stability, referring to frequent premature government terminations. The high power scenario depicts the Austrian tax authorities as very efficient, punishing tax evasion effectively and severely, while the low power scenario describes tax authorities as ineffective regarding prosecution and punishment of tax evasion. The authors test the impact of these media reports on three different outcomes: trust in authorities (i.e., belief that they act in a fair way and on behalf of their citizens), perceived ability to detect tax evasion, and intended tax compliance (i.e., self-reported likelihood of paying one's taxes). Overall, media coverage significantly affects the indicated level of trust in tax authorities and the perceived power of governmental institutions. Both these conditions were also effective in inducing a higher self-reported tax compliance.

Dutta, Murgai, Ravallion, and van de Walle (2013) provide an interesting example of how entertainment movies can be used to convey useful information regarding governmental policy. Their goal is to improve public service delivery in the context of India's "Mahatma Gandhi National Rural Employment Guarantee Scheme" (NREGS), which is the country's largest national antipoverty program. To increase the low participation rates in the state of Bihar, the authors implemented a randomized control trial for an information intervention, in the form of a short movie. This movie conveyed information about rights and entitlements under the program, describing how it works, who is eligible and how to apply. From a sample of 150 villages, 40 were randomly selected for a screening of this movie. Two to four months after the intervention the authors collected a follow-up survey with a variety of outcomes including knowledge, perceptions and usage of the scheme. They found that respondents from treatment villages were significantly more likely to know the key features of NREGS (e.g., number of 
days of work, wage, etc.). They also had more positive perceptions, e.g., regarding increases in employment and decreases in migration due to NREGS, and were more likely to state that economic opportunities had improved for their family in the past year. Interestingly, they were significantly less likely than the control group to believe that women could get work under the scheme - despite this being a feature of the program- possibly because the main character in the movie was male.

The latter point illustrates one of the dangers of conveying information exclusively through entertainment programs, i.e., the possibility that the partial set of information that can fit in a short entertaining product may give a biased perception about complex realities. But the most interesting result in the study by Dutta et al. (2013) is probably the discrepancy between perceived and actual outcomes. In fact, objectively measured employment shows no gain on average, neither on the extensive nor on the intensive margin, suggesting that the movie was effective in changing social perceptions about the scheme but not actual utilization.

\subsection{Attitudes}

In this section, we briefly discuss the relationship between media exposure and individual attitudes, focusing as an example on inter-ethnic attitudes and material aspirations. More specifically, we examine whether exposure to the media can affect deeply rooted prejudice, norms of inter-group cooperation, and individual beliefs about the drivers of success in life.

Studies by Paluck (2009) and Paluck and Green (2009) provide evidence that education entertainment can be effectively used to change perceived social norms. The authors exploit an experiment in Rwanda that used a radio soap opera to promote reconciliation in the country ten years after the genocide. This program, named Musekeweya (New Dawn), was explicitly designed to teach listeners about the roots of violence, the importance of independent thought and the danger of excessive deference to authority. The studies are based on a randomized control trial, where treatment consisted in the reconciliation radio program, while the control group was assigned to listen to a radio soap opera about reproductive health and AIDS. The communities in the study were chosen to represent salient political, regional and ethnic breakdowns of present-day Rwanda: two genocide survivor communities (mostly Tutsi), two Twa communities (the Pygmy minority), two prisons and eight general population communities. Within each category, each community was matched to the most similar one (on the basis of education, gender ratio, quality of dwellings) and one community in each pair was randomly assigned to treatment. Overall, the radio program proved effective in influencing social norms and behaviors, while no effect was found on beliefs. Compared with listeners in the control group, treated listeners' perceptions of social norms and behaviors changed with respect to intermarriage, open dissent, trust, empathy, cooperation and trauma healing, while the radio soap opera did little to change listeners' personal beliefs. 
An important question is whether positive effects on attitudes found in the short run persist in the medium or long run. After all, norms and attitudes are deeply rooted and one may suspect that the effects uncovered in experimental evaluations may be short-lived. Hennighausen (forthcoming) tries to address this concern by investigating if the information provided by mass media have the power to persistently affect individual beliefs about the drivers of success in life. Similar to Bursztyn and Cantoni (forthcoming), she exploits a natural experiment on West German television reception in former East Germany to analyze its impact on East Germans' beliefs before reunification and up to one decade after. While most citizens of East Germany had access to West German television already before reunification, 15 percent of the inhabitants in the Northeastern and Southeastern areas did not, due to geographic characteristics such as distance from transmitters or presence of mountains. This variation allows her to use survey data from the 1980s and test whether exposure to West German programs affected the beliefs of East Germans before reunification. Living in a district without access to Western TV decreases the probability of believing that effort matters for success by 7 percentage points, from a mean of .60 in other parts of Germany. The authors then use data from the German Socio-Economic Panel (GSOEP) during 1994-99 to test if the effects of pre-reunification exposure persist a decade later. She finds that they do: respondents from districts that did not receive West German programs are 3 to 5 percentage points more likely to believe that success in life is a matter of luck.

These findings suggest that Western TV programs vehicled important messages on the relationship between effort and success in life and had a long-lasing effect on the corresponding beliefs of East Germans. Given that beliefs about the determinants of success in life are also correlated with voters' preferences for redistribution (e.g., Fong, 2001; Alesina and La Ferrara, 2002), these findings can have important policy implications: media exposure may affect redistributive preferences and other policy outcomes even if these effects are not intended.

\subsection{Consumption and savings}

Another set of outcomes which can be affected by media exposure include consumption and savings decisions. While we do not cover the substantial literature on the impact of the media on financial choices of investors (see Tetlock, 2015), we summarize two papers on the impact of the media on household consumption and financial choices.

Bursztyn and Cantoni (forthcoming) study the exposure to Western television during the communist regime in East Germany, with a focus on the impact on household consumption. Similar to Hennighausen (forthcoming), they take advantage of the natural experiment created by differential reach of Western signal broadcast across regions of the former German Democratic Republic (GDR) during the communist era. The authors' hypothesis is that exposure to Western TV during the communist regime affected preferences for different consumption 
goods but, because of rationing, the impact on preferences could not translate into consumption choices. However, after reunification, citizens in East Germany have access to the same stores and consumption goods as West Germans, so if television had an impact we would expect differences in consumption for citizens exposed to Western TV after 1990.

Using a difference-in-differences strategy, Bursztyn and Cantoni find that West German TV did not affect aggregate consumption and savings, but rather the composition of consumption. In particular, product categories with high intensity of advertising during the decade before reunification were purchased in higher proportions by East German citizens who had been exposed to Western TV. This result is consistent with long-lasting effects of media exposure, ultimately resulting in imitative behavior as in other papers surveyed in this review.

While the above study examines the effect of "unintentional" exposure to consumption messages, a recent study in South Africa explores the possibility of intentionally embedding information in entertainment programs to affect savings behavior. Berg and Zia (2013) analyze the impact of financial education messages on debt management delivered through the soap opera Scandal!. This soap opera had been running for over eight years, with 4 weekly episodes, and was broadcast by the second most popular TV station in South Africa. In 2012 a sub-plot was included for a period of two months to show the consequences of debt mismanagement and advise on how to avoid debt traps and get out of debt. To address possible concerns related to self-selection into watching the soap opera, the authors adopted a symmetric encouragement design. From a sample of about 1,000 individuals, a randomly selected group was encouraged to watch Scandal!, while the remaining group was encouraged to watch a comparable soap opera that overlapped with Scandal! in television prime time. The encouragement took the form of financial incentives: participants were informed that they would be called on the phone during the weeks in which the soap opera was showing and would be asked some questions about the plot, receiving a monetary compensation in case of mostly correct answers. A follow up questionnaire was added three months later. Berg and Zia found encouraging results: treated individuals had significantly better financial knowledge of the specific issues presented in the soap opera storyline (not better general financial knowledge). Concerning behaviors, viewers of "Scandal?" were almost twice as likely to borrow from formal sources, less likely to engage in gambling, and less prone to enter hire purchase agreements compared to the control group.

These two papers suggest that information and behaviors portrayed on TV can affect consumption and savings choices in ways that are not purely mediated by the advertising role that has traditionally been attributed to television.

\subsection{Development economics}

We have not kept a separate discussion of impacts of the media in developing countries because indeed some of the best evidence comes from these settings, as Table 1 shows. One of the 
earliest empirical papers on the economics of the media was indeed focused on India (Besley and Burgess, 2001). Up to today, important sections of our knowledge on media effects come from studies set in these countries. Notable examples from the contributions discussed in the previous sections include Jensen and Oster (2009) and La Ferrara, Chong and Duryea (2012) for family outcomes in India and Brazil, respectively; Olken (2009) on social capital in Indonesia; Paluck (2009) on inter-ethnic attitudes in Rwanda; and Berge and Zia (2013) on financial choices in South Africa.

Without re-summarizing the impact in developing-country contexts, it is worth emphasizing three natural reasons for the richness of media evidence in these context. The first is the wealth of identifying variation. The uneven speed of development in these economies implies that access to media often arrives suddenly, monopolies of content are not uncommon, and geographic factors, such as those that affect radio reception, provide natural variation in access. In high-income countries, instead, media markets are saturated, and competition between media outlets is so stiff, that idiosyncratic variation in exposure or content across places and over time is hard to find.

A second reason has to do with the scope for impact. Exposure to the media often outlines role models and portrays societies that are particularly different from local behavior. This difference implies that the potential for behavior change is larger. The impact of telenovelas on fertility is a case in point. Telenovelas are common not just in developing countries but in the developed world, and they often involve similar plots and role models. The behavior of such role models, for example with respect to fertility, is, however, more similar to the typical behavior of the audience in developed countries than in developing countries. In turn, this implies that, to the extent that there are peer effects from the role models, these effects will be felt much more in developing countries than in developed settings.

A third reason is that media such as radio and television play an even more important

role in countries with low literacy rates, in which print media has limited diffusion. In these countries there is a particular interest, as we stress in the concluding section, in the role that radio and television can play for educational purposes.

\section{Policy and Conclusion}

Having reviewed the impact of media exposure across a variety of settings, we return to the policy implications briefly outlined in the Introduction. In particular, what are the perspectives for the use of media programming for social policy?

As we discussed, an important opportunity emerges from the complementarity between entertainment and education in the "educational entertainment" (or "edutainment") combination: entertainment shows that incorporate role model lessons. A precedent for this combination is the case of product placement, in which a particular product, such as a particular beer, 
is consumed by a character during a movie or television show. In the case of edutainment, the content placed is not a product, but a social behavior, presented so that it would be imitated, or the opposite. La Ferrara (2015) discusses the underpinnings of this approach from the social psychology literature and its applications to anti-poverty policies.

The studies above on family outcomes highlight the potential of such combination: soap operas played an important role in lowering fertility rates in a country with very high fertility like Brazil. Importantly, this policy impact occurred with no apparent loss of audience. Indeed, the role models in the soap operas were not explicitly designed, as far as we know, to affect social change, but were a by-product of the entertainment plot. The examples of such success stories stress the potential of such interventions.

Other points, however, suggest a cautionary note. We discussed an example regarding migration in which media exposure had the opposite effect of what one may have thought: exposure to higher standard of living reduced, rather than increased, migration. In other cases, exposure to edutainment just had no impact on behavior.

While scattered examples of evaluations exist, it seems that more systematic and rigorous evaluations could greatly help in assessing the effectiveness of edutainment policies across different contexts. Specifically designing evaluations to understand through what channels these programs affect behavior is an exercise still relatively rare in this field. A recent example is the work by Banerjee, La Ferrara and Orozco (2015), who have implemented a randomized control trial to estimate the impact of the MTV series Shuga 3 on risky sexual behavior, gender norms and domestic violence in Nigeria. A key feature of this evaluation is that it embeds in the design the estimation of spillovers and the role that individual ex ante beliefs play in shaping reactions to the program. Future evaluations of edutainment productions would ideally foresee variations in the design, e.g. in the content delivered, to improve our understanding of this potential policy tool.

A different, delicate issue concerns the ethics of the interventions: what are the limits of using commercial television for social development? (Brown and Singhal 1990). Some interventions, like the placement of ethnic examples designed to lead to ethnic reconciliation, are unlikely to be controversial. Yet, other cases are likely to spur controversies. After all, a major motivation for the study of media effects was understanding the exploitation of the media for propaganda purposes by autocratic governments. As part of this manipulation, dictators such as Hitler and Mussolini embedded political messages in entertainment content provided by the state, an early example of edutainment. Which of the modern edutainment applications cross the line from contribution to society to controversial propaganda? More debate on the topic, together with further evidence on the effectiveness of the placed media content, is surely in order.

It is important to add that the policy implications are not limited to the placement of content within entertainment. A general message throughout the paper is the importance of 
the substitution channel for the media effects: so much time is spent on media entertainment that even moderate shifts in the time allocated to media consumption can crowd out, or crowd in, activities with policy relevance. A first example is the study of effects on social capital: the expansion of television takes time away from activities that we tend to think of as having high value added: social interactions and participation in groups providing public goods.

An opposite example emerges from the finding that releases of violent movies lower violent crime because they reduce the allocation of time to even more pernicious activities. This is a surprising policy impact for a media genre that generally is seen very critically. This finding is not likely isolated. More generally, media entertainment that attracts groups with violent inclinations has the potential to play an important positive role.

All in all, the study of the economic and social impacts of the media is an area in transition that exhibits great potential. The large majority of what we know in the area did not even exist ten years ago. That only leads one to imagine what breakthroughs lie ahead for the field. 


\section{References}

\section{References}

[1] Aguiar, M., Hurst, E., and Karabarbounis, L. (2013). "Time Use During the Great Recession." American Economic Review 103(5), 1664-1696.

[2] Alesina, A., and La Ferrara, E. (2002). "Who Trusts Others?" Journal of Public Economics $85(2), 207-234$.

[3] American Academy of Pediatrics (2001). "American Academy of Pediatrics: Children, Adolescents, and Television." Pediatrics 107(2), 423-426.

[4] Anderson, C.A., and Bushman, B.J. (2001). "Effects of Violent Video Games on Aggressive Behavior, Aggressive Cognition, Aggressive Affect, Physiological Arousal, and Prosocial Behavior: A Meta-analytic Review of the Scientific Literature.” Psychological Science 12, 353-359.

[5] Anderson, C.A., Berkowitz, L., Donnerstein, E., Huesmann, L.R., Johnson, J.D., Linz, D., Malamut, N.M. and Wartella, E. (2003). "The Influence of Media Violence on Youth", Psychological Science in The Public Interest 4, 81-110.

[6] Banerjee, A., E. La Ferrara and V. Orozco (2015), "Changing norms and behavior of young people in Nigeria: An evaluation of entertainment TV", mimeo, Bocconi University.

[7] Baron, J. N. and Reiss, P. C. (1985) "Same Time, Next Year: Aggregate Analysis of the Mass Media and Violent Behavior" American Sociological Review 50, 347-363.

[8] Bauman, K.E., LaPrelle, J., Brown, J.D., Koch, G.G., and Padgett, C.A. (1991). "The Influence of Three Mass Media Campaigns on Variables Related to Adolescent Cigarette Smoking: Results of a Field Experiment." American Journal of Public Health, 81(5): 597-604.

[9] Berg, G., and Zia, B. (2013). "Harnessing Emotional Connections to Improve Financial Decisions: Evaluating the Impact of Financial Education in Mainstream Media."World Bank Policy Research Working Paper No. 6407.

[10] Besley, T., and Burgess, R. (2001). "Political Agency, Government Responsiveness and the Role of the Media." European Economic Review 45, 629-640.

[11] Bjorvatn, K., A. Cappelen, L. Helgesson Sekeiz, E. Sørensen, B. Tungodden (2015), "Teaching through television: Experimental evidence on entrepreneurship education in Tanzania", mimeo, NHH Norwegian School of Economics. 
[12] Bollen, K. A., and Phillips, D. P. (1982). "Imitative Suicides: A National Study of The Effects of Television News Stories".American Sociological Review: 802-809.

[13] Bhuller, M., Havnes, T., Leuven, E. and Mostad, M. (2013). "Broadband Internet: An Information Superhighway to Sex Crime?". Review of Economics Studies 80, 1237-1266.

[14] Braga, M. (2007). "Dreaming Another Life: The Role of Foreign Media in Migration Decision-Evidence from Albania."World Bank Working Paper.

[15] Brown, W.J., and Singhal, A. (1990). "Ethical Dilemmas of Prosocial Television." Communication Quarterly 38(3), 1990.

[16] Bursztyn, L. and Cantoni, D. (forthcoming). "A Tear in the Iron Curtain: The Impact of Western Television on Consumption Behavior". Review of Economics and Statistics.

[17] Card, D., and Dahl, G.B. (2011). "Family Violence and Football: The Effect of Unexpected Emotional Cues on Violent Behavior". Quarterly Journal of Economics 126, 1-41.

[18] Cheung, M. (2012). "Edutainment Radio, Women's Status and Primary School Participation: Evidence from Cambodia". Stockholm University, Working Paper.

[19] Chong, A. and La Ferrara, E. (2009). "Television and Divorce: Evidence from Brazilian Novelas" Journal of the European Economic Association: Papers $\&$ Proceedings 7(2-3), 458-468.

[20] Cook, D.E., Kestenbaum, C., Honaker, L.M., and Anderson, E.R., Jr. (2000). Joint Statement on the Impact of Entertainment Violence on Children. Congressional Public Health Summit. http://www2.aap.org/advocacy/releases/jstmtevc.htm

[21] Cunningham, S., Engelstätter, B., and Ward, M.R. (2011). "Understanding the Effects of Violent Video Games on Violent Crime." ZEW Discussion Papers, No. 11-042.

[22] Dahl, G. and DellaVigna, S. (2009). "Does Movie Violence Increase Violent Crime? " Quarterly Journal of Economics 124(2), 677-734.

[23] DellaVigna, S., and Gentzkow, M. (2010). "Persuasion: Empirical Evidence", Annual Review of Economics, 2, 643-669.

[24] DellaVigna, S., and Kaplan, E. (2007) "The Fox News Effect: Media Bias and Voting." Quarterly Journal of Economics 122(2), 807-860.

[25] Dutta, P., Ravallion, M., Murgai, R., and van de Walle, D. (2013). "Testing Information Constraints on India's Largest Antipoverty Program."World Bank, Policy Research Working Paper No. 6598. 
[26] Enikolopov, R. and Petrova, M. (2015). "Media Capture: Empirical Evidence" In: Anderson, S., Strömberg, D., and Waldfogel, J. (Eds.), Handbook of Media Economics, vol. 1. North-Holland, Amsterdam.

[27] Farré, L., and Fasani, F. (2013). "Media Exposure and Internal Migration - Evidence from Indonesia." Journal of Development Economics 102(C), 48-61.

[28] Farrelly, M.C., Nonnemaker, J., Davis, K.C. and Hussin, A. (2009). "The Influence of the National truth Campaign on Smoking Initiation".American Journal of Preventive Medicine, 36(5):379-84.

[29] Fernandes, L. (2000). "Nationalizing 'The Global': Media Images, Cultural Politics, and the Middle Class in India." Media, Culture, $\& 5$ Society 22(5), 611-628.

[30] Fong, C. (2001): "Social Preferences, Self Interest, and the Demand for Redistribution," Journal of Public Economics 82(2), 225-246.

[31] Gentile, D. A., Oberg, C., Sherwood, N.E., Story, M., Walsh, D.A., and Hogan, M. (2004). "Well-Child Visits in the Video Age: Pediatricians and the American Academy of Pediatrics' Guidelines for Children's Media Use." Pediatrics 114(5), 1235-1241.

[32] Gentzkow, M. (2006). "Television and Voter Turnout." Quarterly Journal of Economics 121(3), 931-972.

[33] Gentzkow, M., and Shapiro, J.M. (2008). "Preschool Television Viewing and Adolescent Test Scores Historical Evidence from the Coleman Study." Quarterly Journal of Economics 123(1), 279-323.

[34] Gentzkow, M., Shapiro, J. and Stone, D. (2015) "Media Bias in the Marketplace: Theory" In: Anderson, S., Strömberg, D., and Waldfogel, J. (Eds.), Handbook of Media Economics, vol. 1. North-Holland, Amsterdam.

[35] Groseclose, T. and Milyo, J. (2005). "A Measure of Media Bias", Quarterly Journal of Economics, 120, 1191-1237.

[36] Heckman, J.J. (2000). "Policies to Foster Human Capital." Research in Economics 54(1), $3-56$.

[37] Hennighausen, T. (forthcoming), "Exposure to Television and Individual Beliefs: Evidence from a Natural Experiment." Journal of Comparative Economics, forthcoming.

[38] Huang, F., and Lee, M. (2010). "Dynamic Treatment Effect Analysis of TV Effects on Child Cognitive Development." Journal of Applied Econometrics 25(3), 392-419. 
[39] Hufford, G. (2002) The ITS Irregular Terrain Model, Version 1.2.2: The Algorithm. Institute for Telecommunication Sciences, National Telecommunications and Information Administration. http://www.its.bldrdoc.gov/media/50674/itm.pdf.

[40] Jacobsen, G.D. (2011). "The Al Gore effect: An Inconvenient Truth and voluntary carbon offsets". Journal of Environmental Economics and Management, 61: 67-78.

[41] Jensen, R., and Oster, E. (2009). "The Power of TV: Cable Television and Women's Status in India." The Quarterly Journal of Economics 124(3), 1057-1094.

[42] Johnson, K. (2001). "Media and Social Change: The Modernizing Influences of Television in Rural India." Media, Culture, \& Society 23(2), 147-169.

[43] Johnson, J.G., Cohen, P., Smailes, E.M., Kasen, S., and Brook, J.S. (2002) "Television Viewing and Aggressive Behavior During Adolescence and Adulthood", Science 295, 24682471.

[44] Josephson, W.L. (1987) "Television Violence and Children's Aggression: Testing the Priming, Social Script, and Disinhibition Predictions." Journal of Personality and Social Psychology 53, 882-890.

[45] Kasper, M., Kogler, C. and Kirchler, E. (2015). "Tax Policy and the News: An Empirical Analysis of Taxpayers' Perceptions of Tax-related Media Coverage and its Impact on Tax Compliance." Journal of Behavioral and Experimental Economics 54, 58-63.

[46] Keane, M., and Fiorini, M. (2014). "How the Allocation of Children's Time Affects Cognitive and Non-Cognitive Development." Journal of Labor Economics 32(4), 787-836.

[47] Kearney, M.S., and Levine, P.B. (2014). "Media Influences on Social Outcomes: The Impact of MTV's 16 and Pregnant on Teen Childbearing." NBER Working Paper No. 19795.

[48] Kearney, M.S., and Levine, P.B. (2015). "Early Childhood Education by MOOC: Lessons from Sesame Street". NBER Working Paper No. 21229.

[49] Keefer, P., and Khemani, S. (2011). "Mass Media and Public Services: The Effects of Radio Access on Public Education in Benin."Policy Research Working Paper Series 5559, The World Bank.

[50] Kennedy, M. G., O'Leary, A., Beck, V., Pollard, W. E., and Simpson, P. (2004). "Increases in Calls to The CDC National STD and AIDS Hotline Following AIDS-related Episodes in a Soap Opera." Journal of Communication 54(2), 287-301. 
[51] La Ferrara, E., Chong, A., and Duryea, S. (2012). "Soap Operas and Fertility: Evidence from Brazil." American Economic Journal: Applied Economics 4(4), 1-31.

[52] La Ferrara, E. (2015), "Mass media and social change: Can we use television to fight poverty?", JEEA-FBBVA lecture.

[53] Olken (2009). "Do TV and Radio Destroy Social Capital? Evidence from Indonesian Villages." American Economic Journal: Applied Economics 1(4), 1-33.

[54] Paluck, E.L. (2009), "Reducing intergroup prejudice and conflict using the media: A field experiment in Rwanda", Journal of Personality and Social Psychology, 96, 574-587.

[55] Paluck, E.L., and Green, D.P. (2009). "Deference, Dissent, and Dispute Resolution: A Field Experiment on a Mass Media Intervention in Rwanda." American Political Science Review 103(4), 622-644.

[56] Putnam. (2000). Bowling Alone: The Collapse and Revival of American Community.

[57] Scrase, T.J. (2002). "Television, The Middle Classes and the Transformation of Cultural Identities in West Bengal, India." International Communication Gazette 64(4), 323-342.

[58] Strömberg, D. (2004). "Radio's Impact on Public Spending." Quarterly Journal of Economics 119(1), 189-221.

[59] Strömberg, D. (2015). "Media Coverage and Political Accountability: Theory and Evidence." In: Anderson, S., Strömberg, D., and Waldfogel, J. (Eds.), Handbook of Media Economics, vol. 1. North-Holland, Amsterdam.

[60] Tetlock, P. (2015). "The Role of Media in Finance." In: Anderson, S., Strömberg, D., and Waldfogel, J. (Eds.), Handbook of Media Economics, vol. 1. North-Holland, Amsterdam.

[61] Trujillo, M., and Paluck, E.L. (2011). "The Devil Knows Best: Experimental Effects of a Televised Soap Opera on Latino Trust in Government and Support for The 2010 Census." Analyses of Social Issues and Public Policy 12(1), 113-132.

[62] Vaughan, P., Rogers, E., Singhal, A., and Swalehe, R. (2000). "Entertainment-education and HIV/AIDS Prevention: A Field Experiment in Tanzania." Journal of Health Communications 5(1), 81-100.

[63] Wilbur, K. (2015). "Recent Developments in Mass Media: Digitization and Multitasking." In: Anderson, S., Strömberg, D., and Waldfogel, J. (Eds.), Handbook of Media Economics, vol. 1. North-Holland, Amsterdam. 
[64] Zavodny, M. (2006). "Does Watching Television Rot Your Mind? Estimates of The Effect on Test Scores". Economics of Education Review 25(5), 565-573. 
Table 1. Summary of Papers on the Economic and Social Effects of the Media

\begin{tabular}{|c|c|c|c|c|c|}
\hline Paper & Main Outcome & Media & Country & $\begin{array}{l}\text { Empirical } \\
\text { Strategy }\end{array}$ & Identification \\
\hline \multicolumn{6}{|l|}{ Economics of Education } \\
\hline Zavodny, M. (2006) & Scores in standardized tests & TV & USA & Correlation & Fixed effects and Restriction to Twins \\
\hline Gentzkow, M., and Shapiro, J. M. (2008) & Cognitive and non cognitive outcomes & TV & USA & Natural Experiment & $\begin{array}{l}\text { Variation in years of television introduction across } \\
\text { media markets }\end{array}$ \\
\hline Huang, F., and Lee, M. (2010) & Cognitive outcomes - Math and reading scores & TV & USA & Correlation & Dynamic panel data model with feedback \\
\hline Keane, M., and Fiorini, M. (2012) & Ranking of productivity of different activities & Media & Australia & Correlation & Econometric modelling and exclusion restrictions \\
\hline Kearney, M.S., and Levine, P.B. (2015) & Educational and labor market outcomes & $\begin{array}{l}\text { Exposure to Sesame } \\
\text { Street on PBS } \\
\text { (Television) }\end{array}$ & USA & Natural experiment & $\begin{array}{l}\text { Variation in signal coverage across counties due to } \\
\text { technological features and distance, and in exposure } \\
\text { among cohorts }\end{array}$ \\
\hline Keefer, P., and Khemani, S. (2011) & Share of literate children in the village & Radio & Benin & Natural experiment & Variation in radio coverage across villages \\
\hline \multicolumn{6}{|l|}{ Economics of the Family } \\
\hline $\begin{array}{l}\text { La Ferrara, E., Chong, A., and Duryea, S. } \\
\text { (2012) }\end{array}$ & Fertility rates & Telenovelas (TV) & Brazil & Natural Experiment & $\begin{array}{l}\text { Geographic and temporal variation in access to Rede } \\
\text { Globo network telenovelas }\end{array}$ \\
\hline Chong, A., and La Ferrara, E. (2009) & Divorce rates & Telenovelas (TV) & Brazil & Natural Experiment & $\begin{array}{l}\text { Geographic and temporal variation in access to Rede } \\
\text { Globo network telenovelas }\end{array}$ \\
\hline Jensen, R., and Oster, E. (2009) & $\begin{array}{l}\text { Acceptability of domestic violence, degree of } \\
\text { preference for male children, female } \\
\text { autonomy/decision-making ability, female school } \\
\text { enrollment, fertility }\end{array}$ & TV & India & Natural Experiment & $\begin{array}{l}\text { Geographic and temporal (2001-2003) variation in } \\
\text { access to cable television. }\end{array}$ \\
\hline Cheung, M. (2012) & $\begin{array}{l}\text { School enrollment, Women Status: ideal number of } \\
\text { sons, acceptability of domestic violence, sole final say }\end{array}$ & Radio & Cambodia & Natural Experiment & Geographic and temporal variation in access to radio \\
\hline Kearney, M.S., and Levine, P.B. (2014) & $\begin{array}{l}\text { Talking about related topics: Twitter and Google } \\
\text { searches; Rates of teen childbearing: birth certificates } \\
\text { information }\end{array}$ & $\begin{array}{l}16 \text { and Pregnant } \\
\text { (TV) }\end{array}$ & USA & Correlation/IV & $\begin{array}{l}\text { Panel data/ variation in searching trends/ instrumental } \\
\text { variables }\end{array}$ \\
\hline \multicolumn{6}{|l|}{ LABOR/Migration Decisions } \\
\hline Braga, M. (2007) & Individual migration decisions & TV & Albania & Natural Experiment & $\begin{array}{l}\text { Variation in distance from Italian television } \\
\text { transmitters due to topographic characteristics }\end{array}$ \\
\hline Farré, L., and Fasani, F. (2013) & Migration & TV & Indonesia & Natural Experiment & $\begin{array}{l}\text { Variation in reception due to the topography of the } \\
\text { terrain }\end{array}$ \\
\hline $\begin{array}{l}\text { Bjorvatn, K., A. Cappelen, L. Helgesson } \\
\text { Sekeiz, E. Sørensen, B. Tungodden (2015) }\end{array}$ & Entrepreneurship & $\begin{array}{l}\text { Show on } \\
\text { enterpreneurship } \\
\text { (TV) }\end{array}$ & Tanzania & $\begin{array}{l}\text { Randomized } \\
\text { controlled trial }\end{array}$ & $\begin{array}{l}\text { Randomized encouragement to watch TV show on } \\
\text { entrepreneurship }\end{array}$ \\
\hline
\end{tabular}




\begin{tabular}{|c|c|c|c|c|c|}
\hline \multicolumn{6}{|l|}{ Environmental Economics } \\
\hline Jacobsen, G.D. (2011) & $\begin{array}{l}\text { Environmental friendly behavior: Carbon offsets } \\
\text { purchase }\end{array}$ & \begin{tabular}{|l|} 
Documentary Movie \\
An Inconvenient \\
Truth
\end{tabular} & USA & Natural Experiment & Spatial variation in film release to theaters \\
\hline \multicolumn{6}{|l|}{ Health } \\
\hline \multicolumn{6}{|l|}{ Suicide } \\
\hline Bollen, K.A., and Phillips, D. P. (1982) & Suicide incidence & TV & USA & Event Study & $\begin{array}{l}\text { Compares day/week following the news about } \\
\text { celebrity suicide to other periods }\end{array}$ \\
\hline Baron, J.N., and Reiss, P.C. (1985) & Suicide incidence, homicide incidence & TV & USA & Event Study & $\begin{array}{l}\text { Compares day/week following the news about } \\
\text { celebrity suicide to other periods. Relative to Bollen } \\
\text { and Phillips, Baron and Reiss include additional } \\
\text { controls }\end{array}$ \\
\hline \multicolumn{6}{|l|}{ Smoking } \\
\hline $\begin{array}{l}\text { Bauman, K.E., LaPrelle, J., Brown, J.D., } \\
\text { Koch, G.G., and Padgett, C.A. (1991) }\end{array}$ & $\begin{array}{l}\text { Adolescents - Subjective expected Utility for smoking, } \\
\text { Friends approval, Friends encouragement, smoking } \\
\text { intentions }\end{array}$ & $\begin{array}{l}\text { Anti-smoking } \\
\text { advertisement via } \\
\text { radio }\end{array}$ & USA & Field experiment & $\begin{array}{l}\text { Two MSAs in US South allocated as treatments, four } \\
\text { MSAs as controls }\end{array}$ \\
\hline $\begin{array}{l}\text { Farrelly, M.C., Nonnemaker, J., Davis, K.C. } \\
\text { and Hussin, A. (2009) }\end{array}$ & $\begin{array}{l}\text { Smoking initiation among adolescents aged 12-17 } \\
\text { years }\end{array}$ & $\begin{array}{l}\text { Anti-smoking } \\
\text { Advertisement }\end{array}$ & USA & Natural experiment & $\begin{array}{l}\text { As proxy of exposure Gross Rating Points - indicators of } \\
\text { reach and frequency of a campaign in each media } \\
\text { market - are used }\end{array}$ \\
\hline \multicolumn{6}{|l|}{ HIV/AIDS } \\
\hline $\begin{array}{l}\text { Vaughan, P., Rogers, E., Singhal, A., and } \\
\text { Swalehe, R. (2000) }\end{array}$ & $\begin{array}{l}\text { Communication about HIV, HIV Awareness, } \\
\text { Prevention behaviors, Number of partners }\end{array}$ & Radio Soap Opera & Tanzania & Natural experiment & $\begin{array}{l}\text { Exposure to radio Soap opera with content on HIV } \\
\text { prevention }\end{array}$ \\
\hline $\begin{array}{l}\text { Kennedy, M. G., O'Leary, A., Beck, V., } \\
\text { Pollard, W. E., and Simpson, P. (2004) }\end{array}$ & $\begin{array}{l}\text { Number of calls received by the CDC National STD } \\
\text { and AIDS Hotlines English service }\end{array}$ & $\begin{array}{l}\text { TV Soap opera The } \\
\text { Bold and the } \\
\text { Beautiful }\end{array}$ & USA & $\begin{array}{l}\text { Interrupted time } \\
\text { series design }\end{array}$ & $\begin{array}{l}\text { HIV related episode in soap opera + message with } \\
\text { Hotline Number }\end{array}$ \\
\hline \multicolumn{6}{|l|}{ Crime } \\
\hline Josephson, W.L. (1987) & $\begin{array}{l}\text { Boys' Aggression (as reported by teachers completing } \\
\text { the 9-item Rip van Winkle Peer Rated Index of } \\
\text { Aggression) }\end{array}$ & Short Video & Canada & Experiment & $\begin{array}{l}\text { Random assignment to one of six treatment groups--2 } \\
\text { orders of frustration (before/after TV-watching) } \\
\text { crossed with } 3 \text { TV violence exposure conditions }\end{array}$ \\
\hline Dahl, G. and DellaVigna, S. (2009) & Violent crime & Violent Movies & USA & Natural experiment & $\begin{array}{l}\text { Day-to-day variation in the movie audiences of } \\
\text { strongly violent, mildly violent, and non-violent } \\
\text { movies. }\end{array}$ \\
\hline Card, D. and Dahl, G.B. (2011) & Family violence & $\begin{array}{l}\text { Football game shown } \\
\text { on TV }\end{array}$ & USA & Natural Experiment & $\begin{array}{l}\text { Variation in football score, compared to the predicted } \\
\text { score of the game (Las Vegas bookmakers), comparing } \\
\text { locals fans to other viewers }\end{array}$ \\
\hline $\begin{array}{l}\text { Bhuller, M., Havnes, T., Leuven, E. and } \\
\text { Mogstad, M. (2013) }\end{array}$ & Sex crime and rape and child sex abuse & Internet & Norway & Natural Experiment & $\begin{array}{l}\text { Spatial and temporal variation in access to internet } \\
\text { due to implementation of National Broadband Policy }\end{array}$ \\
\hline $\begin{array}{l}\text { Cunningham, A. S.; Engelstätter, B., Ward, } \\
\text { M. R. (2011) }\end{array}$ & Weekly crime & Video Games & USA & $\begin{array}{l}\text { Instrumental } \\
\text { Variables }\end{array}$ & $\begin{array}{l}\text { Instrument: Ratings of video games by a video games } \\
\text { rating agency, exploiting the variation in game sales } \\
\text { correlated with the variation in quality. }\end{array}$ \\
\hline
\end{tabular}




\begin{tabular}{|c|c|c|c|c|c|}
\hline \multicolumn{6}{|l|}{ Public Economics } \\
\hline Olken, B. (2009) & $\begin{array}{l}\text { Social Capital: trust, participation to social groups, } \\
\text { number of activities in the village; Governance: } \\
\text { attendance at village meetings, quality of discussion, } \\
\text { percentage of funds used in the project }\end{array}$ & Radio and TV & Indonesia & $\begin{array}{l}\text { Instrumental } \\
\text { Variables }\end{array}$ & $\begin{array}{l}\text { Variation in propagation of signal due to topographical } \\
\text { and geographical conformation of the territory }\end{array}$ \\
\hline Trujillo, M., and Paluck, E.L. (2011) & $\begin{array}{l}\text { Support for the US census and attitudes toward } \\
\text { government amongst US latinos }\end{array}$ & $\begin{array}{l}\text { Telenovela Más Sabe } \\
\text { El Diablo (The devil } \\
\text { knows best) }\end{array}$ & USA & $\begin{array}{l}\text { Randomized } \\
\text { controlled trial }\end{array}$ & $\begin{array}{l}\text { Random assignment of subjects into treatment group } \\
\text { exposed to pro-census messaging in a latino soap } \\
\text { opera or into control group exposed to an episode of } \\
\text { the same soap opera not involving the census }\end{array}$ \\
\hline $\begin{array}{l}\text { Kasper, M., Kogler, C., and Kirchler, E. } \\
\text { (2013) }\end{array}$ & Government Trust and Power; Tax compliance & TV & Austria & $\begin{array}{l}\text { Randomized } \\
\text { controlled trial }\end{array}$ & $\begin{array}{l}\text { Assignemnt to } 4 \text { conditions: High vs Low Trust } \\
\text { Scenarios and High vs Low Power Scenarios }\end{array}$ \\
\hline $\begin{array}{l}\text { Dutta, P., Ravallion, M., Murgai, R., and van } \\
\text { de Walle, D. (2013) }\end{array}$ & $\begin{array}{l}\text { Knowledge of BREGS; Perceptions that BREGS } \\
\text { increase employment, reduce migration, enhance } \\
\text { infrastructures; actual or desired participation, wage } \\
\text { rates or days worked. }\end{array}$ & $\begin{array}{l}\text { Movie about rights } \\
\text { under an entitlement } \\
\text { program }\end{array}$ & India & $\begin{array}{l}\text { Randomized } \\
\text { controlled trial }\end{array}$ & Random assignment of villages to screening of movie \\
\hline \multicolumn{6}{|l|}{ Attitudes } \\
\hline Paluck, E.L., and Green, D.P. (2009) & $\begin{array}{l}\text { Beliefs regarding prejudice, violence and trauma; } \\
\text { norms regarding how to behave in situations related } \\
\text { to prejudice, conflict and trauma; behaviors: speak, } \\
\text { dissent and cooperate }\end{array}$ & $\begin{array}{l}\text { Radio Soap Opera } \\
\text { Musekaweya (or } \\
\text { New Dawn) }\end{array}$ & Rwanda & $\begin{array}{l}\text { Randomized } \\
\text { controlled trial }\end{array}$ & $\begin{array}{l}\text { Randomized assignment to radio soap opera versus } \\
\text { control programming }\end{array}$ \\
\hline Hennighausen, T. (forthcoming) & Beliefs about the drivers of success & TV & $\begin{array}{l}\text { Eastern } \\
\text { Germany }\end{array}$ & Natural Experiment & $\begin{array}{l}\text { Variation in access to western television due to } \\
\text { geographical and topographical characteristics of the } \\
\text { territory }\end{array}$ \\
\hline \multicolumn{6}{|l|}{ Consumption and Savings } \\
\hline Bursztyn, L. and Cantoni, D. (forthcoming) & $\begin{array}{l}\text { Disposable income, total private consumption, and } \\
\text { savings; use of financial instruments; consumption } \\
\text { choices }\end{array}$ & TV & $\begin{array}{l}\text { Eastern } \\
\text { Germany }\end{array}$ & Natural Experiment & $\begin{array}{l}\text { Variation in access to western television due to } \\
\text { geographical and topographical characteristics of the } \\
\text { territory }\end{array}$ \\
\hline Berg, G., and Zia, B. (2013) & $\begin{array}{l}\text { General and Specific financial literacy, borrowing } \\
\text { from formal banks, borrowing for investment } \\
\text { purposes, saving propensity, likelihood of using } \\
\text { money for gambling and hire expenses, seek for } \\
\text { financial advice }\end{array}$ & $\begin{array}{l}\text { TV Soap opera } \\
\text { Scandal! }\end{array}$ & South Africa & $\begin{array}{l}\text { Randomized } \\
\text { controlled trial }\end{array}$ & Randomized encouragement to watch soap opera \\
\hline
\end{tabular}

